ARTICLE

https://doi.org/10.1038/s41467-019-10750-8

\title{
Dual pathways of tRNA hydroxylation ensure efficient translation by expanding decoding capability
}

\author{
Yusuke Sakai $^{1,2}$, Satoshi Kimura ${ }^{1,2} \&$ Tsutomu Suzuki id ${ }^{1}$
}

In bacterial tRNAs, 5-carboxymethoxyuridine $\left(\mathrm{cmo}^{5} \mathrm{U}\right)$ and its derivatives at the first position of the anticodon facilitate non-Watson-Crick base pairing with guanosine and pyrimidines at the third positions of codons, thereby expanding decoding capabilities. However, their biogenesis and physiological roles remained to be investigated. Using reverse genetics and comparative genomics, we identify two factors responsible for 5-hydroxyuridine (ho ${ }^{5} \mathrm{U}$ ) formation, which is the first step of the $\mathrm{cmo}^{5} \mathrm{U}$ synthesis: TrhP (formerly known as $\mathrm{YegQ}$ ), a peptidase U32 family protein, is involved in prephenate-dependent ho ${ }^{5} \mathrm{U}$ formation; and TrhO (formerly known as YceA), a rhodanese family protein, catalyzes oxygen-dependent ho ${ }^{5} \mathrm{U}$ formation and bypasses $\mathrm{cmo}^{5} \mathrm{U}$ biogenesis in a subset of tRNAs under aerobic conditions. E. coli strains lacking both trhP and trhO exhibit a temperature-sensitive phenotype, and decode codons ending in G (GCG and UCG) less efficiently than the wild-type strain. These findings confirm that tRNA hydroxylation ensures efficient decoding during protein synthesis.

\footnotetext{
${ }^{1}$ Department of Chemistry and Biotechnology, Graduate School of Engineering, University of Tokyo, 7-3-1 Hongo, Bunkyo-ku, Tokyo 113-8656, Japan.

${ }^{2}$ These authors contributed equally: Yusuke Sakai, Satoshi Kimura. Correspondence and requests for materials should be addressed to

T.S. (email: ts@chembio.t.u-tokyo.ac.jp)
} 
$\mathrm{R}$ NA modifications confer chemical diversity on simple RNA molecules, expanding their functional repertoires. To date, more than 140 species of RNA modifications have been identified in RNA molecules from all domains of life ${ }^{1}$.

In protein synthesis, tRNA serves as an adapter molecule to connect codons on mRNA with the corresponding amino acids. After they are transcribed, tRNAs undergo chemical modifications mediated by site-specific tRNA-modifying enzymes. These modifications play critical roles in stabilizing tRNA tertiary structure and fine-tuning the decoding process ${ }^{2,3}$. A wide variety of modifications are present at the first (wobble) position of the anticodon in tRNA (position 34). The wobble modification modulates codon recognition, thereby promoting accurate decoding during protein synthesis ${ }^{3,4}$.

In the original wobble rule ${ }^{5}$, guanosine at the wobble position (G34) base-pairs with $\mathrm{U}$ and $\mathrm{C}$ at the third letter of the codon, likewise, uridine at the wobble position (U34) base-pairs with A and $\mathrm{G}$ at the third letter of the codon. In Mycoplasma species and mitochondria ${ }^{6-8}$, however, U34 recognizes any of the four bases in a family box through a mechanism called four-way wobbling ${ }^{3}$. To decode two codon sets ending in purine (NNR), $\mathrm{U} 34$ is frequently modified to 5-methyl-(2-thio)uridine derivatives $\left[\mathrm{xm}^{5}\left(\mathrm{~s}^{2}\right) \mathrm{U}\right]$ : 5-carboxymethylaminomethyl-(2-thio)uridine $\left[\mathrm{cmnm}^{5}\left(\mathrm{~s}^{2}\right) \mathrm{U}\right]$ and 5-methylaminomethyl-(2-thio)uridine $\left[\mathrm{mnm}^{5}\left(\mathrm{~s}^{2}\right) \mathrm{U}\right]$ in bacterial tRNAs, 5-methoxycarbonylmethyl(2-thio)uridine $\left[\mathrm{mcm}^{5}\left(\mathrm{~s}^{2}\right) \mathrm{U}\right]$ and its derivatives in eukaryotic cytoplasmic tRNAs, and 5-taurinomethyl-(2-thio)uridine [ $\mathrm{\tau m}^{5}$ $\left.\left(s^{2}\right) \mathrm{U}\right]$ in mitochondrial tRNAs ${ }^{3}$. These modifications prevent tRNAs from misreading near-cognate codons ending in pyrimidines $(\mathrm{NNY})^{9}$. In addition, $\mathrm{xm}^{5}\left(\mathrm{~s}^{2}\right) \mathrm{U} 34$ plays a critical role in stabilizing U-G wobble pairing at the A-site of the ribosome $\mathrm{e}^{10,11}$.

In contrast to $\mathrm{xm}^{5}\left(\mathrm{~s}^{2}\right) \mathrm{U}$-type modifications, 5-hydroxyuridine derivatives $\left(\mathrm{xo}^{5} \mathrm{U}\right)$ are present at the wobble positions of tRNAs responsible for NYN family boxes, and serve to expand decoding capacity in most bacterial species (Fig. 1a, b). To date, four species of $\mathrm{xo}^{5} \mathrm{U}$ modifications have been reported. 5carboxymethoxyuridine $\left(\mathrm{cmo}^{5} \mathrm{U}\right.$, also called uridine-5-oxy acetic acid) and 5-methoxycarbonylmethoxyuridine $\left(\mathrm{mcmo}^{5} \mathrm{U}\right.$, also called uridine-5-oxy acetic acid methyl ester) are found in Gram-negative bacteria, including Escherichia coli and Salmonella enterica ${ }^{2,12}$. 5methoxycarbonylmethoxy-2'O-methyluridine $\left(\mathrm{mcmo}^{5} \mathrm{Um}\right)$ was recently detected in $E$. coli $\mathrm{tRNA}^{\mathrm{Ser}}$ as a minor modification ${ }^{13}$. In addition, 5-methoxyuridine $\left(\mathrm{mo}^{5} \mathrm{U}\right)$ is present in tRNA ${ }^{\mathrm{Thr}}$ from Gram-positive bacteria, including Bacillus subtilis ${ }^{14}$. Using mass spectrometry, we revealed that $\mathrm{cmo}^{5} \mathrm{U} 34$ is present as a major wobble modification in tRNA ${ }^{\text {Leu3 } 3}$ and tRNA ${ }^{\text {Vall }}$, whereas $\mathrm{mcmo}^{5} \mathrm{U} 34$ is primarily present in $\mathrm{tRNA}^{\mathrm{Ala} 1}, \mathrm{tRNA}^{\mathrm{Ser} 1}$, $\mathrm{tRNA}^{\text {Pro3 }}$, and tRNA ${ }^{\text {Thr4 }}$ in E. coli ${ }^{13}$ (Fig. 1b). The xo ${ }^{5} \mathrm{U}$-type modifications facilitate non-Watson-Crick base pairing with guanosine and pyrimidines at the third positions of codons ${ }^{15-18}$ (Fig. 1b), thereby contributing to expansion of decoding capability. Moreover, the terminal methylation of $\mathrm{mcmo}^{5} \mathrm{U}$ contributes to decoding ability, at least in tRNA Ala1 13.

A structural study of $\mathrm{cmo}^{5} \mathrm{U}$ nucleoside in solution revealed that $\mathrm{cmo}^{5} \mathrm{U}$ adopts the $\mathrm{C} 2$ '-endo ribose pucker conformation, providing mechanistic insight into base pairing with pyrimidines 9 . The crystal structures of codon-anticodon interactions at the ribosomal A-site revealed that the $\mathrm{O} 5$ atom of $\mathrm{cmo}^{5} \mathrm{U}$ is involved in an intramolecular hydrogen bond that pre-structures the anticodon loop, enabling $\mathrm{cmo}^{5} \mathrm{U}$ to pair with pyrimidines at the third position of the codon ${ }^{19}$. In addition, $\mathrm{cmo}^{5} \mathrm{U}$ pairs with $\mathrm{G}$ in standard Watson-Crick geometry, rather than classical U-G wobble geometry, indicating that keto-to-enol tautomeric conversion of the uracil base is involved in this base pairing interaction $^{19}$.
Multistep reactions are involved in the biosynthetic pathway of $\mathrm{cmo}^{5} \mathrm{U}$ and $\mathrm{mcmo}^{5} \mathrm{U}$ in bacterial tRNAs (Fig. 1c). Three enzymes, $\mathrm{CmoA}, \mathrm{CmoB}$, and $\mathrm{CmoM}$, are involved in the second to last step in the pathway. Initially, U34 is hydroxylated to form 5-hydroxyuridine $\left(\mathrm{ho}^{5} \mathrm{U}\right)$ in a reaction catalyzed by unidentified factors. Chorismate, an end product of the shikimate pathway, is involved in this step, but the source of the oxygen atom remains unknown ${ }^{20}$. On the other hand, the subsequent steps have been elucidated. In the second step, a unique carboxymethyl donor, $S$ carboxymethyl-S-adenosyl-L-homocysteine (SCM-SAH, also called (Xx-SAM) is synthesized from AdoMet and prephenate in a reaction catalyzed by $\mathrm{CmoA}^{21,22}$. $\mathrm{CmoB}$ then transfers the carboxymethyl group of SCM-SAH to ho ${ }^{5} \mathrm{U} 34$ to form $\mathrm{cmo}^{5} \mathrm{U} 34$ on tRNA $^{21}$. In four tRNA species (for Ser1, Pro3, Thr4, and Ala1), $\mathrm{cmo}^{5} \mathrm{U}$ is further methylated by $\mathrm{CmoM}$ to form $\mathrm{mcmo}^{5} \mathrm{U}_{3} 4^{13}$. The terminal methylation of $\mathrm{mcmo}^{5} \mathrm{U}$ in tRNA ${ }^{\text {Pro3 }}$ dynamically alters its modification frequency in a growth phase-dependent manner ${ }^{13}$.

Hydroxylation of RNA molecules is a major posttranscriptional modification that plays roles in multiple biological contexts. In addition to $\mathrm{xo}^{5} \mathrm{U}$ modification of bacterial tRNAs, RNA hydroxylation is also responsible for the biogenesis and function of eukaryotic RNA modifications. The JmjC domaincontaining protein TYW5 is responsible for biogenesis of hydroxywybutosine (OHyW) at position 37 of mammalian tRNA Phe23. ALKBH1 catalyzes tRNA hydroxylation to form 5hydroxymethyl-2'O-methylcytidine $\left(\mathrm{hm}^{5} \mathrm{Cm}\right)$ and 5-formyl-2'Omethylcytidine $\left(\mathrm{f}^{5} \mathrm{Cm}\right)$ in cytoplasmic tRNA ${ }^{\mathrm{Leu}}$, as well as 5formylcytidine $\left(\mathrm{f}^{5} \mathrm{C}\right)$ in mammalian mitochondrial tRNA ${ }^{\mathrm{Met} 24}$. ALKBH1-knockout cells exhibit respiratory defects, indicating that ALKBH1 is required for efficient mitochondrial activity. Recently, we discovered hydroxy- $N^{6}$-threonylcarbamoyladenosine $\left(\mathrm{ht}^{6} \mathrm{~A}\right)$ in echinoderm mitochondrial tRNA; ${ }^{25}$ this modification alters the genetic code in echinoderm mitochondria. $\mathrm{N}^{6}$ methyladenosine $\left(\mathrm{m}^{6} \mathrm{~A}\right)$ and 1-methyladenosine $\left(\mathrm{m}^{1} \mathrm{~A}\right)$ are demethylated by ALKBH family proteins via hydroxymethyl formation 26,27 . The Tet protein is responsible for forming 5hydroxymethylcytidine $\left(\mathrm{hm}^{5} \mathrm{C}\right)$ in Drosophila mRNAs ${ }^{28}$. All of the hydroxylases, including the JmjC, ALKBH, and Tet families, are $\mathrm{Fe}(\mathrm{II})$ - and 2-oxoglutarate (2-OG)-dependent oxygenases that use a molecular oxygen as a substrate for hydroxylation ${ }^{29}$. Recently, we identified RlhA as a factor responsible RNA hydroxylation to form 5 -hydroxycytidine $\left(\mathrm{ho}^{5} \mathrm{C}\right)$ at position 2501 in $E$. coli $23 \mathrm{~S} \mathrm{rRNA}^{30}$. RlhA does not have any characteristic motifs conserved among the known RNA oxygenases, but it does belong to a family of proteins bearing the peptidase U32 motif. This finding encouraged us to explore other peptidase U32containing proteins responsible for hydroxylation of biological molecules.

To search for genes responsible for RNA modifications, we developed a method called ribonucleome analysis to screen knockout strains for uncharacterized genes by liquid chromatography-mass spectrometry (LC/MS) ${ }^{31}$. If a target RNA modification is absent in a certain knockout strain, we can identify the gene dedicated to biogenesis of the target RNA modification via reverse genetics. Using this approach, we have discovered dozens of genes responsible for RNA modifications in tRNAs $^{13,23,32-39}$ and rRNAs ${ }^{30,40,41}$. In this study, we apply ribonucleome analysis in conjunction with comparative genomics to identify two genes, $\operatorname{trh} P$ and $\operatorname{trhO}$, which are responsible for formation of ho ${ }^{5} \mathrm{U}$ at the initial step of $\mathrm{xo}^{5} \mathrm{U}$ biogenesis at the wobble position of bacterial tRNAs. TrhP, a peptidase U32 family protein, is involved in prephenate-dependent ho ${ }^{5} \mathrm{U} 34$ formation. TrhO, a rhodanese family protein, catalyzes oxygen-dependent ho ${ }^{5} \mathrm{U} 34$ formation under aerobic conditions. These two pathways play redundant roles in ho ${ }^{5} \mathrm{U} 34$ formation. Double knockout of 
a

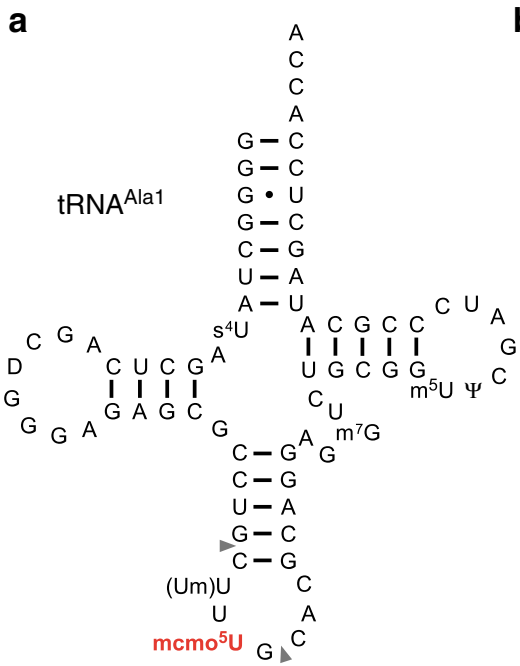

b

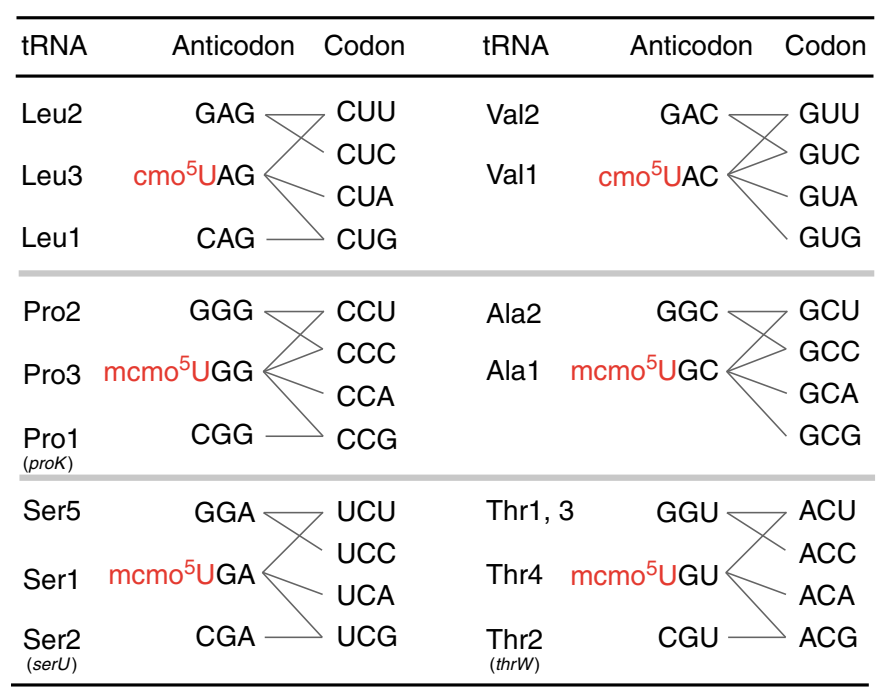

C

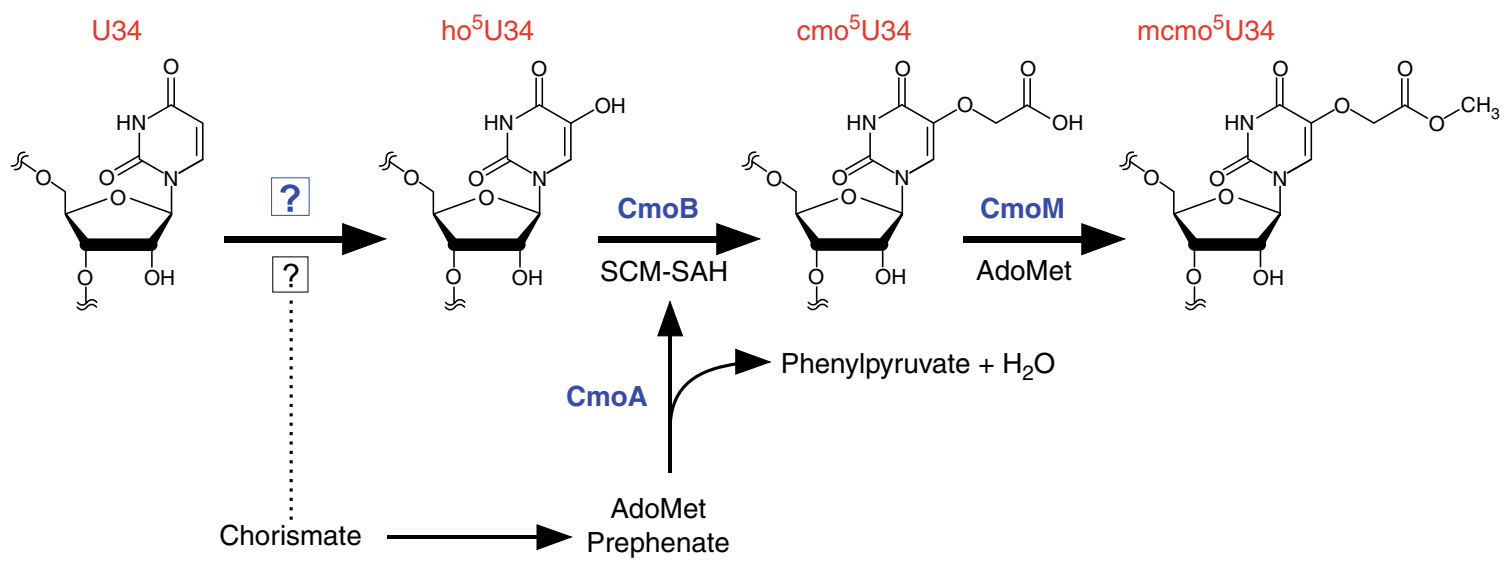

Fig. 1 Decoding capacity of tRNAs is expanded by $(\mathrm{m}) \mathrm{cmo}^{5} \mathrm{U}$. a Secondary structure of E. coli tRNAAla1 with post-transcriptional modifications: 4thiouridine $\left(s^{4} U\right)$, dihydrouridine $(D), 2^{\prime}-O$-methyluridine $(U m), 5$-methoxycarbonylmethoxyuridine $\left(m c m 0^{5} U\right), 7$-methylguanosine $\left(m^{7} G\right), 5$ methyluridine $\left(\mathrm{m}^{5} \mathrm{U}\right)$, and pseudouridine $(\Psi)$. A pair of gray triangles indicate the RNase $\mathrm{T}_{1}$ cleavage positions for analysis of RNA fragments containing the wobble position. $\mathbf{b}$ Anticodon-codon pairing in six codon boxes decoded by tRNAs bearing $\mathrm{cmo}^{5} \mathrm{U}$ and $\mathrm{mcmo}^{5} \mathrm{U}$. Each of the three tRNA genes in parenthesis was individually deleted. In the family boxes (four codons specify a single amino acid), many codons are redundantly decoded by two or three isoacceptors (tRNAs charging with the same amino acid). For example, CUU codon is decoded by TRNA A Leu2 with GAG anticodon as well as tRNALeu3 with $\mathrm{cmo}^{5} \mathrm{UAG}$ anticodon. c Scheme of $\mathrm{mcmo}^{5} \mathrm{U}$ biosynthesis in E. coli. First, U34 is hydroxylated by reactions involving unknown enzymes and substrates to form ho ${ }^{5} \mathrm{U} 34$ in tRNAs responsible for decoding NYN codons. This reaction requires the chorismate biogenesis pathway. CmoA employs prephenate and AdoMet to generate SCM-SAH with the release of phenylpyruvate and water. Then, ho ${ }^{5} \mathrm{U} 34$ is carboxymethylated by $\mathrm{CmoB}$ using SCM-SAH. Finally, tRNAs responsible for decoding NCN codons are further methylated to generate $\mathrm{mcmo}^{5} \mathrm{U}$ by $\mathrm{CmoM}$ in the presence of AdoMet

both enzymes causes a temperature-sensitive phenotype and decreases the efficiency with which codons ending in G (GCG and UCG) were decoded, indicating that ho ${ }^{5} \mathrm{U} 34$ formation ensures efficient decoding during translation.

\section{Results}

E. coli yegQ is involved in tRNA hydroxylation. We recently reported that $\mathrm{RlhA}$ is responsible for $\mathrm{ho}^{5} \mathrm{C}$ formation at position 2501 in E. coli $23 \mathrm{~S}$ rRNA $^{30}$. RlhA belongs to a family of proteins that contain the peptidase U32 motif. This finding prompted us to speculate that other paralogs of peptidase U32-containing proteins are involved in ho ${ }^{5} \mathrm{U} 34$ formation in tRNAs. The E. coli genome contains four paralogs of peptidase U32-containing proteins: $r l h A, y e g Q, y h b U$, and $y h b V$ (Supplementary Fig. 1, Supplementary Data 1). We extracted total RNA from each of the respective knockout strains, digested with RNase $T_{1}$, and subjected the digests to capillary LC-nano-ESI-mass spectrometry (RNA-MS) to detect tRNA fragments containing $\mathrm{cmo}^{5} \mathrm{U}$ (shotgun analysis). RNA fragments were detected as multiply charged negative ions (Supplementary Table 1). We clearly detected an anticodon-containing RNA fragment of tRNA Val1 from total RNA of wild-type (WT) E. coli cells (Fig. 2a). As reported previously ${ }^{13}, \mathrm{cmo}^{5} \mathrm{U} 34$ was present as a major wobble modification in this tRNA, whereas little unmodified fragment (U34) was detected. In a knockout strain lacking yegQ ( $\Delta y e g Q)$, which encodes a peptidase U32-containing protein, $\mathrm{cmo}^{5} \mathrm{U} 34$ frequency decreased markedly, to about $30 \%$ of the WT level, and a corresponding fragment containing unmodified U34 appeared, indicating that $y e g Q$ is partially responsible for the initial step of $\mathrm{cmo}^{5} \mathrm{U} 34$ formation. We reasoned that other paralogs of peptidase U32-containing proteins might be involved in this process. Accordingly, we constructed a quadruple mutant strain, $\Delta y e g Q /$ $\Delta y h b U / \Delta y h b V / \Delta r l h A$, lacking all paralogs of peptidase U32containing proteins, and analyzed the RNA fragment of tRNAVal1. However, the $\mathrm{cmo}^{5} \mathrm{U} 34$-containing fragment persisted in this strain (Fig. 2a), clearly indicating that another hydroxylation 
a

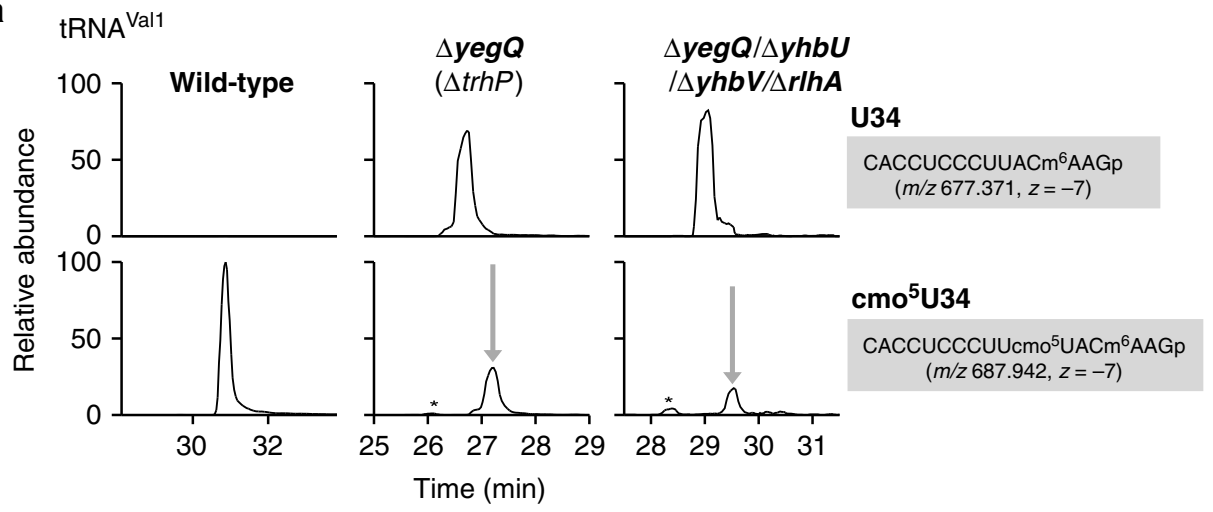

b

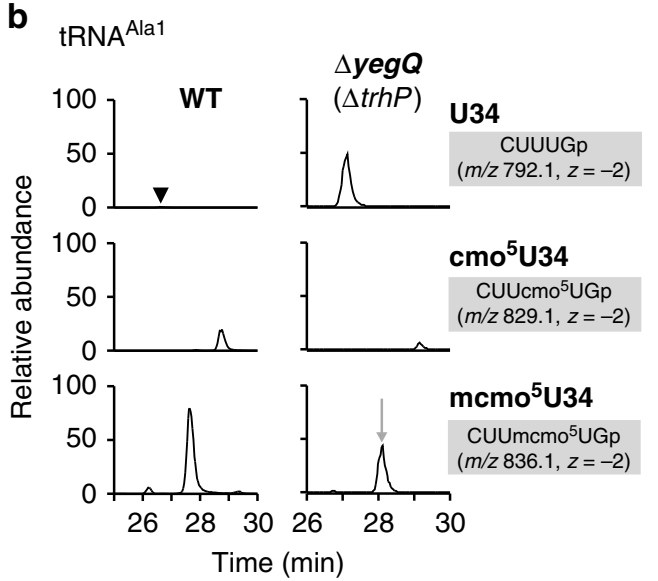

C

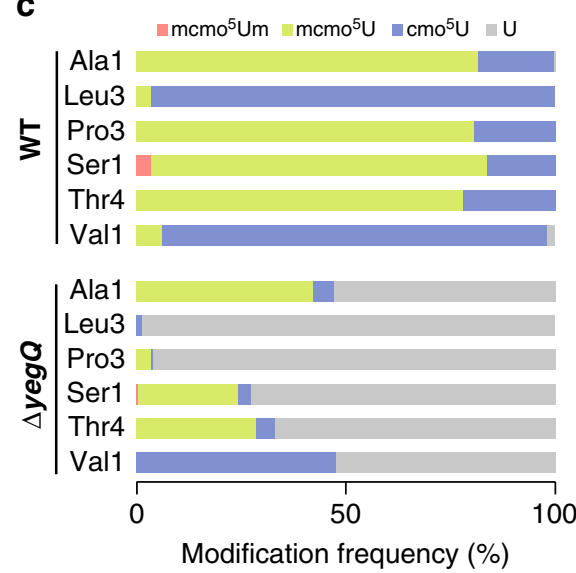

Modification frequency $(\%)$

d

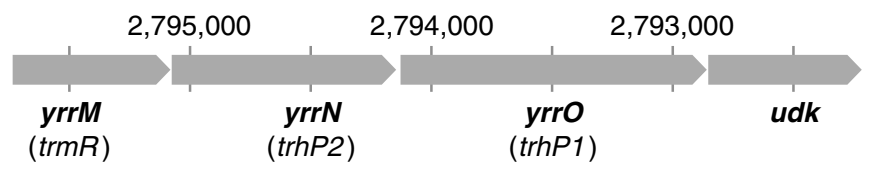

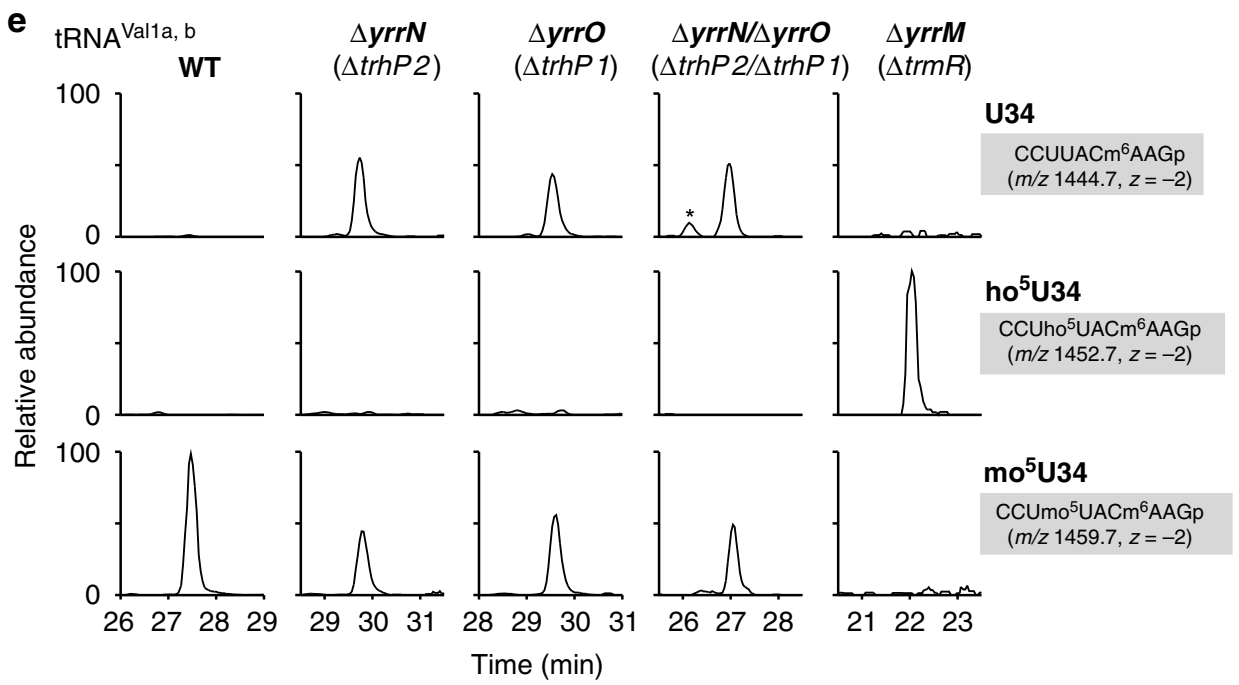

pathway plays a redundant role in the formation of ho ${ }^{5} \mathrm{U} 34$ in tRNAs.

To analyze the modification status of each tRNA species in the $\Delta y e g Q$ strain, we used the reciprocal circulating chromatography (RCC) method $^{42}$ to isolate six tRNA species (tRNA Ala1, tRNA ${ }^{\text {Leu3 } 3}$, tRNA ${ }^{\text {Pro3 }}$, tRNA ${ }^{\text {Ser1 }}$, tRNA Thr4, and tRNA ${ }^{\text {Val1 }}$ ) bearing a $\mathrm{cmo}^{5} \mathrm{U} 34$ or $\mathrm{mcmo}^{5} \mathrm{U} 34$ modification from both WT and $\Delta$ yegQ strains. Each tRNA was digested by RNase $\mathrm{T}_{1}$ and subjected to RNA-MS to analyze the anticodon-containing fragments (Fig. 2b, Supplementary Fig. 2, Supplementary Table 1). Hypomodified fragments were further sequenced by collisioninduced dissociation (CID) analysis (Supplementary Fig. 3). In tRNA ${ }^{A l a 1}, \mathrm{mcmo}^{5} \mathrm{U} 34$ was present as a major wobble modification in the WT, but its levels were reduced to about 50\% (concomitant with appearance of the unmodified fragment) in byegQ (Fig. 2b). Similarly, $\mathrm{mcmo}^{5} \mathrm{U} 34$ levels were reduced in 
Fig. 2 Identification of trhP responsible for tRNA hydroxylation. a Mass-spectrometric shotgun analysis of total tRNAs in E. coli strains. Extracted ion chromatograms (XICs) show multiply charged negative ions of the anticodon-containing fragments of tRNA ${ }^{V a l 1}$ with U34 (upper panels) and $\mathrm{cmo}{ }^{5} \mathrm{U} 34$ (lower) in total tRNAs from wild-type (left), $\Delta y e g Q$ (center), and $\Delta y e g Q / \Delta y h b U / \Delta y h b V / \Delta r / h A$ strains (right). Sequence, $m / z$ value, and charge state of each fragment are shown on the right. Asterisks indicate nonspecific peaks with the same $m / z$ values. b Mass-spectrometric analysis of the wobble modification in E. coli tRNA ${ }^{\text {Ala1 }}$ isolated from WT (left panels) and $\triangle$ yegQ (right) strains. XICs show anticodon-containing fragments of tRNA ${ }^{\text {Ala1 } 1}$ with U34 (top panels), $\mathrm{cmo}^{5} \mathrm{U} 34$ (middle panels), and mcmo $\mathrm{U}_{34}$ (bottom panels). The cleavage sites of RNase $\mathrm{T}_{1}$ are shown in Fig. 1a. It is assumed that $\mathrm{cmo} \mathrm{F}^{5} \mathrm{U}$ detected in this tRNA was generated by artificial hydrolysis of $\mathrm{mcmo}^{5} \mathrm{U}$ during tRNA isolation ${ }^{13}$. The black arrowhead indicates a small peak corresponding to the U34-containing fragment detected in the WT. c Modification frequencies of $\mathrm{cmo}^{5} \mathrm{U}$ derivatives at the wobble position of six tRNA species isolated from WT and $\Delta y e g Q$ strains. Relative compositions of each modification were calculated from the peak area ratio of mass chromatograms of RNase $T_{1}$ digest fragments containing $\mathrm{mcmo}^{5} \mathrm{Um}$ (red), $\mathrm{mcmo}^{5} \mathrm{U}$ (green), $\mathrm{cmo}^{5} \mathrm{U}$ (blue), or $\mathrm{U}$ (gray) at the wobble position (Supplementary Fig. 2) ${ }^{13}$. Source data are provided as a Source Data file. d Gene organization of a B. subtilis operon containing yrrM, yrrN, and yrrO. Genomic positions in B. subtilis are indicated. The new name for each gene is shown in parenthesis. e Mass-spectrometric shotgun analysis of total tRNAs in B. subtilis strains. XICs are shown of doubly charged negative ions of the anticodon-containing fragments of tRNAValla,b with U34 (top panels), ho $\mathrm{U}^{34}$ (middle panels), and mo ${ }^{5} \mathrm{U} 34$ (bottom panels) in total tRNA from wild-type (leftmost panels), $\Delta y r r N$ (left panels), $\Delta y r r O$ (middle panels), $\Delta y r r N / \Delta y r r O$ (right panels), and $\Delta y r r M$ (rightmost panels) strains

tRNA $^{\text {Ser1 }}$ and tRNA ${ }^{\text {Thr4 }}$ from $\Delta y e g Q$ (Fig. 2c, Supplementary Fig. 2). The level of $\mathrm{cmo}^{5} \mathrm{U} 34$, a major modification in WT tRNA $^{\text {Vall, }}$, was also reduced about $50 \%$ in $\Delta y e g Q$ (Fig. 2c, Supplementary Fig. 2). By contrast, the levels of $\mathrm{cmo}^{5} \mathrm{U} 34$ of tRNA $^{\text {Leu3 }}$ and $\mathrm{mcmo}^{5} \mathrm{U} 34$ of $\mathrm{tRNA}^{\text {Pro3 }}$ dropped sharply, to less than $5 \%$ of WT levels, in the $\Delta y e g Q$ strain (Fig. 2c, Supplementary Fig. 2). These results indicate that yegQ is involved differently in ho ${ }^{5} \mathrm{U} 34$ formation in each tRNA. In particular, tRNA ${ }^{\text {Leu3 }}$ and tRNA $^{\text {Pro3 }}$ are major targets of YegQ. Accordingly, we renamed yegQ as $\operatorname{trhP}$ (tRNA hydroxylation $\underline{\mathrm{P}}$ ).

Biogenesis of mo5 ${ }^{5} 34$ in Bacillus subtilis. Instead of $\mathrm{cmo}^{5} \mathrm{U} 34$ or $\mathrm{mcmo}^{5} \mathrm{U} 34$, B. subtilis uses $\mathrm{mo}^{5} \mathrm{U} 34$ as an $\mathrm{xo}^{5} \mathrm{U}$-type wobble modification. Upon depletion of intracellular AdoMet, $\mathrm{mo}^{5} \mathrm{U}$ is replaced by $h^{5} \mathrm{U}^{43}$, indicating that $\mathrm{ho}^{5} \mathrm{U}$ is the precursor and AdoMet is the methyl donor for $\mathrm{mo}^{5} \mathrm{U}$ formation. We identified two orthologs of $\operatorname{trhP}$ in B. subtilis, yrrN and yrrO (Supplementary Fig. 1, Supplementary Data 1), both of which are encoded tandemly in the same operon (Fig. 2d). YrrO has a peptidase U32 motif and a characteristic C-terminal motif also found in E. coli TrhP, whereas YrrN only has a peptidase U32 motif.

We investigated whether these two genes are actually involved in $\mathrm{mo}^{5} \mathrm{U} 34$ formation by shotgun analysis of total RNAs extracted from B. subtilis $\Delta y r r N$ and $\triangle y r r O$ strains. Similar to our observation in the E. coli $\Delta t r h P$ strain (Fig. 2a), mo ${ }^{5} \mathrm{U} 34$ frequency in tRNA Vall decreased, and an RNA fragment containing unmodified U34 appeared, in both $\Delta y r r N$ and $\Delta y r r O$ strains (Fig. 2e), indicating that both $y r r N$ and $y r r O$ were necessary for hydroxylation of $\mathrm{U} 34$ to form ho ${ }^{5} \mathrm{U} 34$ in B. subtilis. Accordingly, we renamed $y r r O$ and $y r r N$ as $\operatorname{trhP} 1$ and $\operatorname{trhP2}$, respectively. To determine whether these two paralogs act redundantly to form $\mathrm{ho}^{5} \mathrm{U} 34$, we constructed the doubledeletion strain $\Delta \operatorname{trhP1/\Delta trhP2}$ and analyzed the modification status of tRNA. The same level of mo ${ }^{5} \mathrm{U} 34$ was detected in this strain as in the single-knockout strains (Fig. 2e), suggesting that both paralogs are involved in synthesizing about $50 \%$ of mo5 $\mathrm{U}_{34}$ in the cell, and another pathway is required for the remainder, as also observed for formation of $\mathrm{cmo}^{5} \mathrm{U} 34$ in E. coli.

We then focused on $y r r M$, which is encoded within the same operon as trhP1 and trhP2 (Fig. 2d). B. subtilis YrrM has high sequence similarity to the AdoMet-dependent catechol $O$ methyltransferase that catalyzes methylation of the hydroxyl group on the aromatic ring, suggesting that this protein is a methyltransferase responsible for $\mathrm{mo}^{5} \mathrm{U} 34$ formation. As expected, $\mathrm{mo}^{5} \mathrm{U} 34$ in tRNA ${ }^{\text {Vall }}$ disappeared and was converted to ho ${ }^{5} \mathrm{U} 34$ in a $\Delta y r r M$ strain (Fig. 2e). We then generated recombinant YrrM protein and performed in vitro reconstitution of $\mathrm{mo}^{5} \mathrm{U} 34$ in $E$. coli $\mathrm{tRNA}^{\mathrm{Thr} 4}$ containing ho ${ }^{5} \mathrm{U} 34$, which had been isolated from a $\Delta c m o B$ strain. $m^{5} \mathrm{U} 34$ was successfully synthesized in the presence of both YrrM and AdoMet (Supplementary Fig. 4). The product was confirmed by CID analysis (Supplementary Fig. 4). Taken together, these findings indicate that YrrM is an AdoMet-dependent methyltransferase that converts ho ${ }^{5} \mathrm{U} 34$ to $\mathrm{mo}^{5} \mathrm{U} 34$ in $B$. subtilis. During the preparation of this manuscript, $B$. subtilis yrr $M$ was demonstrated to be a ho ${ }^{5} \mathrm{U} 34$-methyltransferase and renamed $\operatorname{trm}^{44}$.

Alternative pathway for tRNA hydroxylation. E. coli $\operatorname{trh} P$ and $B$. subtilis trhP1/trhP2 are partially involved in the initial step of $\mathrm{cmo}^{5} \mathrm{U} 34$ and $\mathrm{mo}^{5} \mathrm{U} 34$ formation, respectively, indicating the existence of another redundant pathway for ho ${ }^{5} \mathrm{U} 34$ formation in both species. To search for the gene(s) responsible for this pathway, we used a comparative genomic approach. In bacteria, we found several organisms with $c m o A$ and $c m o B$ homologs, but no trhP homolog (Fig. 3a). Similarly, some bacteria had a trmR homolog, but no trhP homologs (Fig. 3a). Given that ho ${ }^{5} \mathrm{U} 34$ is a common precursor for $\mathrm{cmo}^{5} \mathrm{U} 34$ synthesis mediated by $\mathrm{cmoA}$ and $c m o B$, and $\mathrm{mo}^{5} \mathrm{U} 34$ synthesis mediated by $\operatorname{trmR}$, the bacterial species lacking trhP homologs should have another gene responsible for ho ${ }^{5} \mathrm{U} 34$ formation independent of the trhP pathway. We identified seven bacterial species with $c m o A B$ or trmR homologs but no trhP or trhP1/trhP2 homologs (Fig. 3a). Among 4746 E. coli ORFs, we selected 141 genes (Fig. 3b) commonly present in all seven species, as well as in B. subtilis. We then narrowed down the list of candidates to seven genes with unknown functions (Fig. 3b). Among them, a yceA homolog was identified as a strong candidate because its genomic locus is close to that of $c m o A$ in cyanobacteria, and $y c e A$ is encoded as a fusion protein with $\operatorname{trmR}$ in three bacterial species, Phytophthora sojae, Phytophthora ramorum, and Phaeodatylum tricornutum (Fig. 3b). To determine whether $y c e A$ is responsible for the second pathway of ho ${ }^{5} \mathrm{U} 34$ formation, we isolated tRNA ${ }^{\text {Vall }}$ from $E$. coli knockout strains of $\operatorname{trh} P$ and $y c e A$, and analyzed the status of wobble modifications. The residual $\mathrm{cmo}^{5} \mathrm{U} 34$ observed in the $\Delta t r h P$ strain completely disappeared in the double-deletion strain $\Delta t r h P / \Delta y c e A$ (Fig. 3c), indicating that $y c e A$ is responsible for the second pathway of ho ${ }^{5} \mathrm{U} 34$. Hereafter, we refer to $y c e A$ as $\operatorname{trhO}$ (tRNA hydroxylation $\mathrm{O}$ ). However, the amount of unmodified $\overline{\mathrm{U}} 34$-containing fragment increased slightly in the single-deletion strain $\Delta t r h O$ (Fig. $3 \mathrm{c}$ ), indicating that the $t r h P$-mediated pathway plays the predominant role in ho ${ }^{5} \mathrm{U} 34$ formation especially in the absence of $t$ rhO.

B. subtilis $y b f Q$ is an ortholog of E. coli trhO. To determine whether $y b f Q$ is involved in the second pathway for ho ${ }^{5} \mathrm{U} 34$ formation in B. subtilis, we constructed a triple-knockout strain, $\Delta t r h P 1 / \Delta t r h P 2 / \Delta y b f Q$, and analyzed the status of tRNA wobble 
a

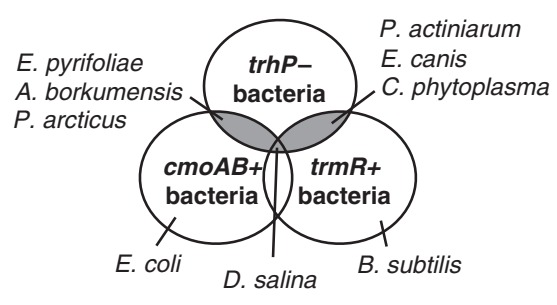

b

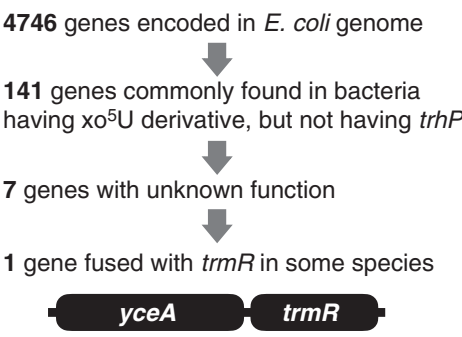

C

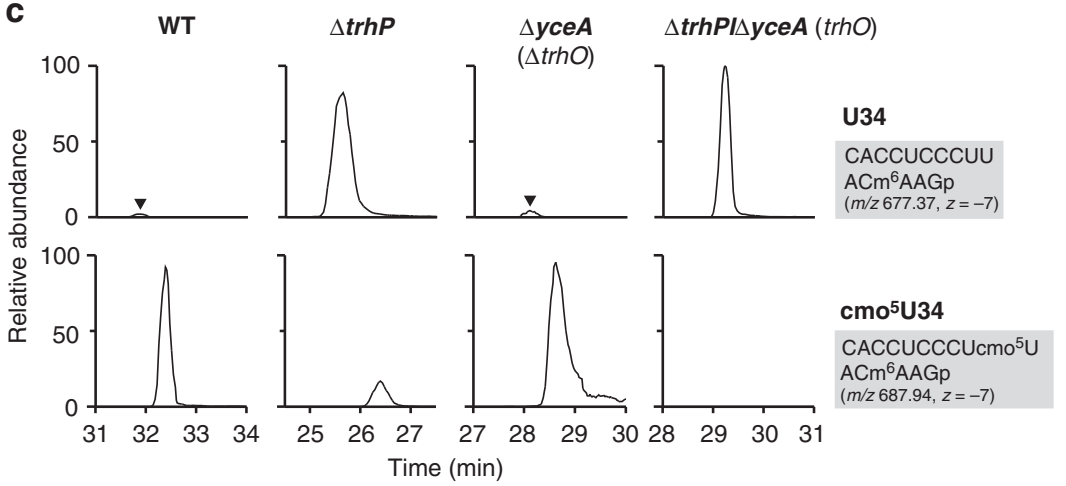

Fig. 3 Identification of trhO responsible for tRNA hydroxylation. a Venn diagram depicts a group of organisms that have $c m o A B$ or trmR homologs but no trhP homologs. Erwinia pyrifoliae, Alcanivorax borkumensis, and Psychrobacter arcticus harbor cmoAB but not trhP; Pontibacter actiniarum, Ehrlichia canis, and Candidatus phytoplasma harbor trmR but not trhP; and Dactylococcopsis salina has both $c m o A B$ and trmR but not trhP. b Comparative genomics approach used to narrow down the candidate gene that bypasses ho ${ }^{5} \mathrm{U} 34$ biogenesis. In Phytophthora sojae, Phytophthora ramorum, and Phaeodatylum tricornutum, yceA and trmR are fused as a single gene. c Mass-spectrometric analysis of the wobble modification in E. coli tRNAVal1 isolated from WT (left panels), $\triangle$ trhP (middle left panels), $\Delta y c e A$ (middle right panels), and $\Delta$ trhP/ $\Delta y c e A$ (right panels) strains. XICs show anticodon-containing fragments of tRNAVal1 with U34 (upper panels) and $\mathrm{cmo}^{5} \mathrm{U} 34$ (lower panels). Black arrowheads indicate peaks corresponding to U34-containing fragments detected in the WT and $\Delta y c e A$. Sequence, $\mathrm{m} / \mathrm{z}$ value, and charge state of each fragment are shown on the right

modifications. The modified $\mathrm{mo}^{5} \mathrm{U} 34$ in the $\Delta \operatorname{trhP} 1 / \Delta \operatorname{trh} P 2$ strain, which was present at about $50 \%$ of the WT level, completely disappeared in the triple-deletion strain (Supplementary Fig. 5). However, as observed in the E. coli $\Delta t r h O$ strain, little reduction in the $\mathrm{mo}^{5} \mathrm{U} 34$ level was observed in the single-deletion strain $\triangle y b f Q$ (Supplementary Fig. 5).

Phylogenetic distribution of $\operatorname{trh} P$ and $\operatorname{trhO}$. To investigate the phylogenetic distribution of $\operatorname{trh} P, \operatorname{trh} P 1, \operatorname{trh} P 2$, and $\operatorname{trh} O$, we generated a phylogenetic tree of organisms possessing or lacking each homolog (Supplementary Fig. 6, Supplementary Data 2). trhO orthologs predominated in bacteria and eukaryotes $(40 \%$; 232 of 584), whereas trhP orthologs (yegQ type in Supplementary Fig. 1) and trhP1/trhP2 orthologs (PepU32\#5/PepU32\#3 in Supplementary Fig. 1) were only present in bacteria, and were less widely distributed [14\% (84 of 584) and 5\% (32 of 584), respectively] (Supplementary Fig. 6, Supplementary Data 2). trhP orthologs were mainly detected in $\gamma$ - and $\beta$-proteobacteria, in addition to some desulfobacteria in $\delta$-proteobacteria. $\operatorname{trhP} 1 / \operatorname{trhP} 2$ orthologs always co-occurred, and were present in phylum Firmicutes and some members of Tenericutes and Cyanobacteria. Given that TrhP1 is a related family with TrhP (Supplementary Fig. 1), TrhP1 might have branched out from TrhP, and evolved to require a paralogous protein TrhP2 that might be generated by gene duplication. Supporting this speculation, trhP1 and $\operatorname{trhP2}$ are tandemly encoded in the same operon in B. subtilis (Fig. 2e). Also, we can explain the reason why trhP orthologs and trhP1/trhP2 orthologs show a mutually exclusive distribution in bacteria (Supplementary Fig. 6). Intriguingly, over half of organisms bearing trhP or trhP1/trhP2 orthologs also harbor trhO orthologs [49 of 84 (58\%) organisms bearing trhP, $P=0.0003$ (Fisher's exact test); 22 of 32 (69\%) organisms bearing
trhP1/trhP2, $P=0.0007$ (Fisher's exact test)] (Supplementary Fig. 7). This significant overlap suggests that harboring both pathways for tRNA hydroxylation might help organisms to adapt to two different environments, i.e., aerobic and anaerobic conditions.

Phenotypes of $\boldsymbol{E}$. coli strains lacking tRNA hydroxylation. We then measured the growth rate of a series of $E$. coli knockout strains involved in $(\mathrm{m}) \mathrm{cmo}^{5} \mathrm{U} 34$ modifications. No growth reduction was observed in the $\triangle c m o M$ strain, as reported previously $^{13}$ (Fig. 4a), indicating that the terminal methylation of mcmo ${ }^{5} \mathrm{U} 34$ has little impact on cell growth. A slight increase of doubling time was observed in the $\triangle c m o B$ strain, in which ho ${ }^{5} \mathrm{U} 34$ accumulated, indicating that the carboxymethyl group of (m) $\mathrm{cmo}^{5} \mathrm{U} 34$ contributes to efficient growth of $E$. coli cells. Notably, the $\Delta t r h P / \Delta t r h O$ strain grew more slowly than the WT and $\triangle c m o B$ strains, providing a clear evidence for the functional importance of 5-hydroxyl group of $(\mathrm{m}) \mathrm{cmo}^{5} \mathrm{U} 34$ in cells. To characterize phenotypic features of the $\Delta t r h P / \Delta t r h O$ strain, we further knocked out tRNA genes responsible for G-ending codons $\left[\operatorname{ser} U\left(\mathrm{tRNA}^{\mathrm{Ser} 2}\right)\right.$ for the UCG codon, $t h r W\left(\mathrm{tRNA}^{\mathrm{Th} 2}\right)$ for the ACG codon, and proK (tRNA ${ }^{\text {Prol}}$ ) for the CCG codon], because these codons are redundantly deciphered by the respective tRNA and the isodecoder with the $(\mathrm{m}) \mathrm{cmo}^{5} \mathrm{U} 34$ modification in each codon box. Growth reduction of the $\Delta t r h P / \Delta t r h O$ strain relative to the $\Delta c m o B$ strain was observed upon knockout of $\operatorname{ser} U$, thrW, and proK (Fig. 4a), indicating that the 5-hydroxyl group of (m) $\mathrm{cmo}^{5} \mathrm{U} 34$ plays a critical role in deciphering G-ending codons, especially in the absence of the respective isodecoder.

Next, we examined the temperature sensitivity of a series of knockout strains involved in $(\mathrm{m}) \mathrm{cmo}^{5} \mathrm{U} 34$ modifications. The $\Delta t r h P / \Delta t r h O / \Delta \operatorname{ser} U$ strain grew as efficiently as the other strains 
a

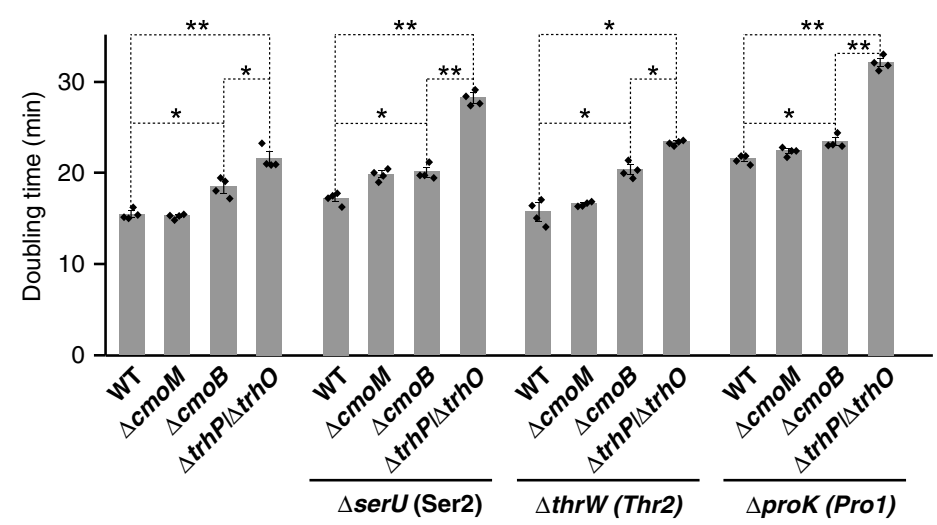

b
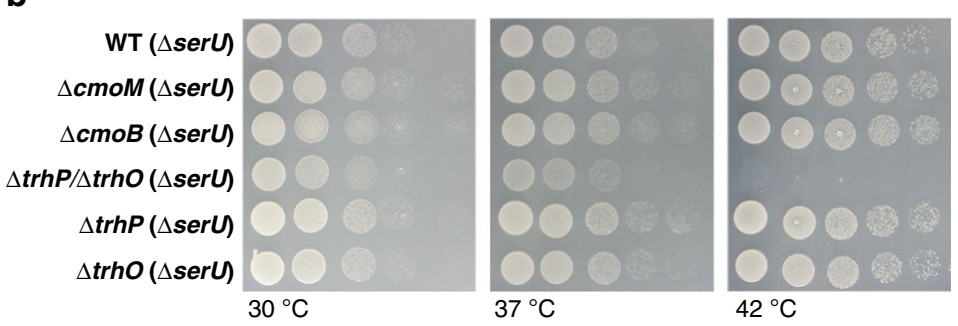

(Mod. status)

$\mathrm{mcmo}^{5} \mathrm{U}$

$\mathrm{cmo}^{5} \mathrm{U}$

$\mathrm{ho}^{5} \mathrm{U}$

U

$\mathrm{U}, \mathrm{mcmo}^{5} \mathrm{U}$

$\mathrm{mcmo}^{5} \mathrm{U}$

C
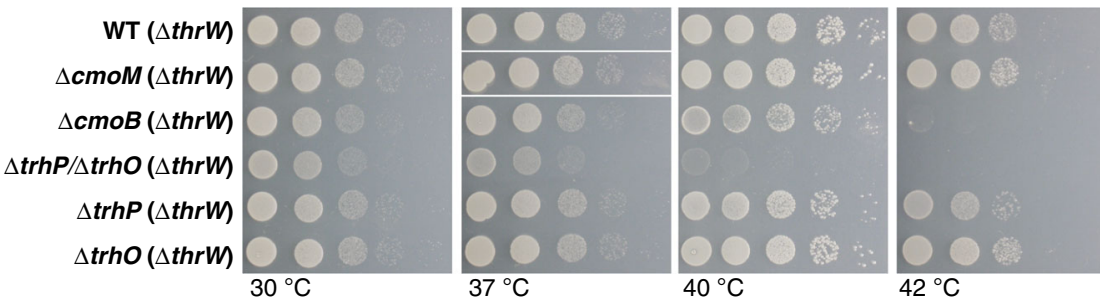

(Mod. status)

mcmo $^{5} \mathrm{U}$

$\mathrm{cmo}^{5} \mathrm{U}$

ho5

U

$\mathrm{U}, \mathrm{mcmo}^{5} \mathrm{U}$

mcmo $^{5} \mathrm{U}$

d

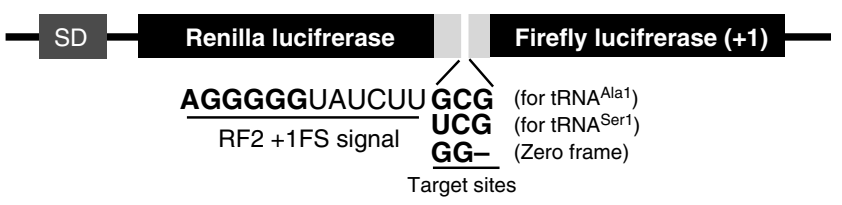

e
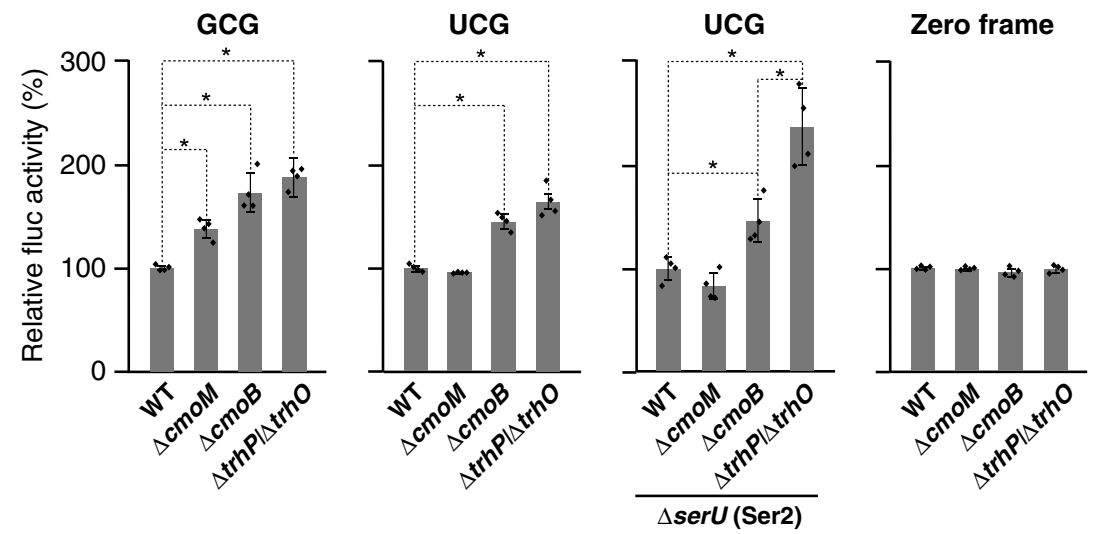

on LB plates at $30^{\circ} \mathrm{C}$, but slowly at $37^{\circ} \mathrm{C}$ and not at all at $42^{\circ} \mathrm{C}$ (Fig. 4b). The growth defect of this strain at $42^{\circ} \mathrm{C}$ was restored by introduction of plasmid-encoded $\operatorname{trh} P$ (Supplementary Fig. 8), indicating that the temperature-sensitive phenotype of this strain can be attributed to hypomodification of tRNA ${ }^{\text {Ser1 }}$. Curiously, the $\Delta \operatorname{trh} P / \Delta \operatorname{ser} U$ strain did not exhibit temperature sensitivity, although the frequency of $\mathrm{mcmo}^{5} \mathrm{U} 34$ actually decreased in
tRNA ${ }^{\text {Ser1 }}$ (Fig. 2c), indicating that trhO-mediated hydroxylation compensates for the growth defect when the trhP-mediated hydroxylation pathway is impaired. This result highlights the importance of redundant hydroxylation pathways for formation of $\mathrm{xo}^{5} \mathrm{U}$. Similarly, we observed a severe growth reduction in the $\Delta t r h P / \Delta t r h O / \Delta t h r W$ strain cultivated on $\mathrm{M} 9$ minimum plates, even at $40^{\circ} \mathrm{C}$ (Fig. $4 \mathrm{c}$ ). At $42^{\circ} \mathrm{C}$, this strain was unable to grow, 
Fig. 4 Phenotypes of $E$. coli strains lacking tRNA hydroxylation. a Growth rates of $E$. coli strains with different wobble modifications. Doubling time of WT

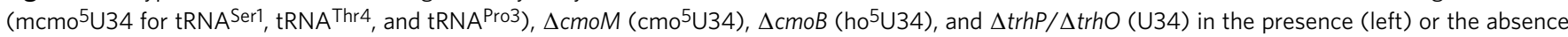
of tRNA isodecoders at $37^{\circ} \mathrm{C}$ in liquid LB medium: tRNA ${ }^{\text {Ser2 }}$ (middle left), tRNAThr2 (middle right), or tRNA Pro1 (right). Individual data (dot plots) and their means \pm SD (bar graph) are presented $(n=4) .{ }^{\star} P<0.01$; ${ }^{\star \star} P<0.001$ between two data series (Student's $t$-test, one-sided). b Growth of WT, $\Delta c m o M$, $\Delta \mathrm{cmoB}, \Delta \operatorname{trhP} / \Delta \operatorname{trhO}, \Delta \operatorname{trhP}$, and $\Delta \operatorname{trhO}$ strains in the absence of tRNA ${ }^{\operatorname{Ser} 2}(\Delta \operatorname{ser} U)$. The expected wobble modification status of each strain is shown on the right. Each strain was serially diluted (1:10), spotted onto LB agar plates, and cultivated for $11 \mathrm{~h}\left(30^{\circ} \mathrm{C}\right), 8 \mathrm{~h}\left(37^{\circ} \mathrm{C}\right)$ or $8 \mathrm{~h}\left(42^{\circ} \mathrm{C}\right)$. c Growth of WT, $\Delta c m o M, \Delta c m o B, \Delta t r h P / \Delta t r h O, \Delta t r h P$, and $\Delta t r h O$ strains in the absence of tRNA Thr2 ( $\Delta$ thrW). The expected wobble modification of each strain is shown on the right. Each strain was serially diluted $(1: 10)$, spotted onto $M 9$ minimum agar plates, and cultivated for $31 \mathrm{~h}\left(30^{\circ} \mathrm{C}\right), 21 \mathrm{~h}\left(37^{\circ} \mathrm{C}\right), 26 \mathrm{~h}\left(40{ }^{\circ} \mathrm{C}\right)$ or $31 \mathrm{~h}$ $\left(42^{\circ} \mathrm{C}\right)$. d Schematic of the reporter construct for the dual-luciferase assay, based on the RF2 recoding system. SD, Shine-Dalgarno sequence. Renilla and firefly luciferases were fused with a linker containing the +1 frameshift inductive signal of the RF2 recoding site. The frameshift target site was replaced with a GCG codon for tRNA ${ }^{A l a 1}$, a UCG codon for tRNA ${ }^{\text {Ser1 }}$, or GG (zero frame) for the control. e Relative pausing activities at the frameshift site with a GCG codon (left), a UCG codon in the presence (middle left) or absence (middle right) of isodecoder tRNA Ser2, or zero frame (right) were calculated by normalizing Fluc activity vs. Rluc activity and further normalizing against the WT activity in each graph. Individual data and their means \pm SD $(n=4)$ are presented. ${ }^{\star} P<0.01$ between two data series (Student's $t$-test, two-sided). All source data for Fig. 4 are provided as a Source Data file

and $\triangle c m o B$ strain exhibited a growth defect. These results clearly demonstrated that the absence of the 5-hydroxyl group of (m) $\mathrm{cmo}^{5} \mathrm{U} 34$ causes a temperature-sensitive phenotype, especially in the absence of the isodecoder responsible for G-ending codons.

Decoding properties without tRNA hydroxylation. To investigate the functional role of $(\mathrm{m}) \mathrm{cmo}^{5} \mathrm{U} 34$ modification in terms of decoding efficiency, we conducted dual-luciferase reporter assays based on the RF2 recoding system ${ }^{18,45}$. The reporter constructs consisted of Renilla luciferase (Rluc) fused with firefly luciferase (Fluc) in a +1 frame via a slippery linker derived from the +1 frameshift signal of the RF2 recoding site, so that Fluc expression requires $\mathrm{a}+1$ frameshift at the linker sequence. The UGA codon at the recoding site was substituted with GCG and UCG as test codons to examine their ability to be decoded by tRNA ${ }^{\text {Ala1 }}$ and tRNA $^{\text {Serl, }}$, respectively (Fig. $4 d$ ). We also prepared a control reporter in which the recoding site was replaced with GG (zero frame). These reporters were introduced to a series of $E$. coli knockout strains lacking genes involved in $(\mathrm{m}) \mathrm{cmo}^{5} \mathrm{U} 34$ modifications. The decoding ability of tRNAs with different wobble modifications at each test codon of the frameshift site was negatively correlated with the +1 frameshift activity, measured by Fluc activity, because in this system the +1 frameshift activity is promoted by the hungry A-site. The +1 frameshift activity was calculated by normalizing the Fluc signal against the Rluc signal (F/R value). No difference in F/R value in the control construct (zero frame) was observed in any strains (Fig. 4e).

Using this system, we first measured decoding ability of tRNA Ala1 with different wobble modifications using the GCGreporter, because in E. coli the GCG codon is solely deciphered by this tRNA (Fig. 1b). Compared with the WT strain ( $\left.\mathrm{mcmo}^{5} \mathrm{U} 34\right)$, we observed clear stimulation of +1 frameshift activity in $\triangle c m o M$ ( $\left.\mathrm{cmo}^{5} \mathrm{U} 34\right)$ and $\triangle \mathrm{cmoB}\left(\mathrm{ho}^{5} \mathrm{U} 34\right)$ strains (Fig. 4e), as reported previously ${ }^{13}$. We also observed a significant increase in +1 frameshift activity in the $\Delta t r h P / \Delta t r h O(\mathrm{U} 34)$ strain relative to the WT strain $\left(\mathrm{mcmo}^{5} \mathrm{U} 34\right)$ (Fig. $\left.4 \mathrm{e}\right)$. These results indicate that tRNA ${ }^{\text {Ala1 }}$ gradually loses its decoding ability in response to sidechain shortening of $\mathrm{mcmo}^{5} \mathrm{U} 34$. Next, we measured the decoding ability of tRNA ${ }^{\text {Ser1 }}$ with different wobble modifications using the UCG-reporter. In E. coli, UCG codons are redundantly decoded by tRNA ${ }^{\text {Ser1 }}$ with the $\mathrm{mcmo}^{5} \mathrm{UGA}$ anticodon and tRNA ${ }^{\mathrm{Ser} 2}$ with the CGA anticodon (Fig. 1b). Relative to the WT strain (mcmo $\left.{ }^{5} \mathrm{U} 34\right)$, we observed a marked increase in +1 frameshift activity in the $\Delta c m o B\left(h^{5} \mathrm{U} 34\right)$ and $\Delta t r h P / \Delta t r h O(\mathrm{U} 34)$ strains (Fig. 4e). Then, we measured the activities of the UCG-reporter in a series of knockout strains in the absence of $\operatorname{tRNA}^{\mathrm{Ser} 2}(\Delta \operatorname{ser} U$ background). Relative to the $\Delta \operatorname{ser} U$ strain $\left(\mathrm{mcmo}^{5} \mathrm{U} 34\right),+1$ frameshift activity was elevated in both $\Delta c m o B / \Delta \operatorname{ser} U\left(\right.$ ho $\left.^{5} \mathrm{U} 34\right)$ and $\Delta \operatorname{trhP} / \Delta \operatorname{trhO} / \Delta \operatorname{serU}(\mathrm{U} 34)$ strains (Fig. 4e). Notably, $\Delta \operatorname{trhP} /$
$\Delta$ trhO/ $\Delta \operatorname{serU}$ (U34) had significantly higher +1 frameshift activity than $\Delta c m o B / \Delta \operatorname{ser} U$ (ho ${ }^{5} \mathrm{U} 34$ ) (Fig. 4e), indicating that the 5-hydroxyl group of ho ${ }^{5} \mathrm{U} 34$ on tRNA ${ }^{\text {Serl }}$ can decode the UCG codon, especially in the absence of isodecoder tRNA ${ }^{\text {Ser2 }}$.

Characterization of $t r h P$-mediated tRNA hydroxylation. According to our recent study ${ }^{30}$, the shikimate pathway is associated with $r$ lhA-mediated ho ${ }^{5} \mathrm{C} 2501$ formation in $23 \mathrm{~S}$ rRNA. A series of genetic studies revealed that prephenate is an essential metabolite for the first step of this modification. Given that TrhP belongs to a family of peptidase U32-containing proteins, we asked whether prephenate is also required for trhP-mediated ho ${ }^{5} 34$ formation. Consistent with this possibility, previous studies reported that the initial step of $\mathrm{cmo}^{5} \mathrm{U} 34$ formation is associated with chorismate biogenesis in E. coli, B. subtilis, and Salmonella typhimurium ${ }^{20,46}$. Chorismate is an end product of the shikimate pathway and a common precursor for aromatic amino acids and vitamins in bacteria and plants ${ }^{47}$. Shotgun analyses of $E$. coli total RNA revealed that $\mathrm{cmo}^{5} \mathrm{U} 34$ formation was significantly impaired in an $\triangle a r o C$ strain, in which no chorismate was produced (Supplementary Fig. 9). However, ho ${ }^{5} \mathrm{U} 34$ was still present in this strain because ho ${ }^{5} \mathrm{U} 34$ was redundantly synthesized by the trhO-mediated pathway. By contrast, as expected, no ho ${ }^{5} \mathrm{U} 34$ was detected in an $\Delta$ aroC/ $\Delta t r h O$ strain (Supplementary Fig. 10). In E. coli, chorismate is converted into five metabolites: isochorismate (catalyzed by the products of entC and menF), 4-hydroxybenzoate (ubiC), 4-amino-4deoxychorismate $(p a b B)$, anthranilate $(\operatorname{trp} E)$, and prephenate (pheA and tyrA) (Fig. 5a). Among these pathways, the ubiCmediated pathway was excluded because 4-hydroxybenzoate does not restore $\mathrm{cmo}^{5} \mathrm{U} 34$ formation in Salmonella $\Delta$ aroD strain ${ }^{46}$. As observed in the $\triangle a r o C$ strain, $\mathrm{cmo}^{5} \mathrm{U} 34$ formation was only impaired in the $\triangle p h e A / \Delta t y r A$ strain, but not in the $\Delta e n t C l$ $\triangle m e n F, \triangle p a b B$, and $\Delta \operatorname{trpE}$ strains (Supplementary Fig. 9), indicating that prephenate or its downstream metabolites are required for ho ${ }^{5} \mathrm{U} 34$ formation.

Prephenate is converted to downstream metabolites via three pathways (Fig. 5a). $\mathrm{cmo}^{5} \mathrm{U} 34$ formation was unchanged in $\triangle t y r A$ and $\Delta t y r B$ strains (Supplementary Fig. 9). pheA encodes a fusion of chorismate mutase (CM) and prephenate dehydratase (PDT), which synthesize prephenate and phenylpyruvate, respectively (Fig. 5a). To dissect these two enzymatic activities, we constructed a pheA variant possessing only the $\mathrm{CM}$ activity [pheA(CM)] by introducing an active-site mutation in the PDT domain ${ }^{48}$. To determine whether prephenate is responsible for ho ${ }^{5} \mathrm{U} 34$ formation, we constructed the quadruple-knockout strain $\Delta p h e A / \Delta t y r A / \Delta c m o A / \Delta t r h O$, and then introduced plasmidencoded pheA(CM), resulting in accumulation of prephenate. ho ${ }^{5} \mathrm{U} 34$ levels were restored relative to those in a mock 
a

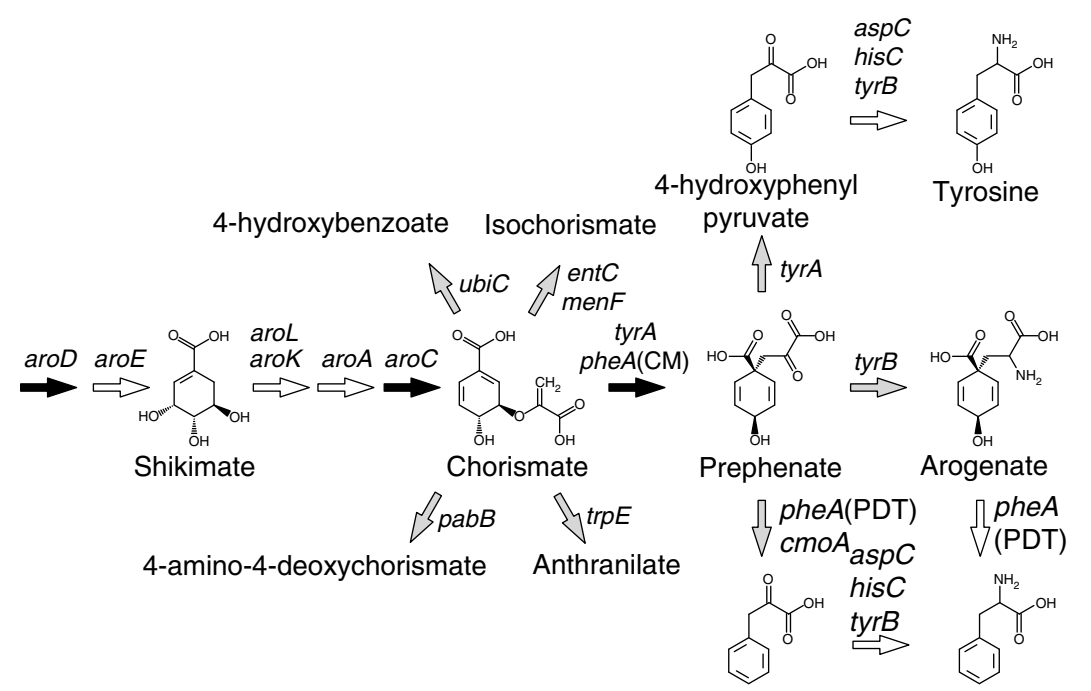

b

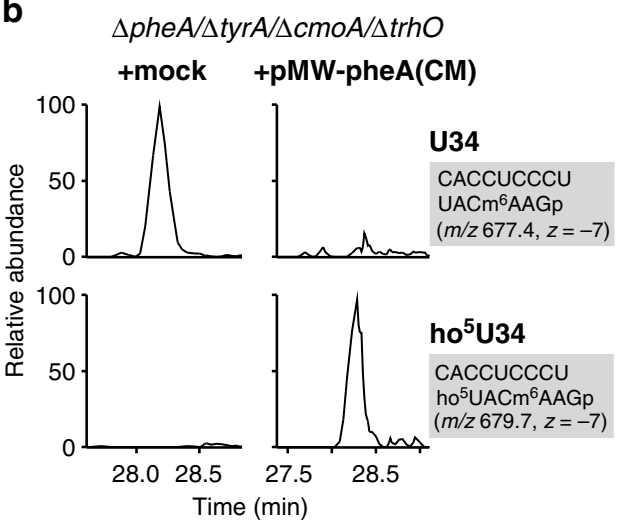

Phenylpyruvate Phenylalanine

C $\quad \Delta p h e A / \Delta t y r A / \Delta c m o A / \Delta t r h O$

Control tprephenate

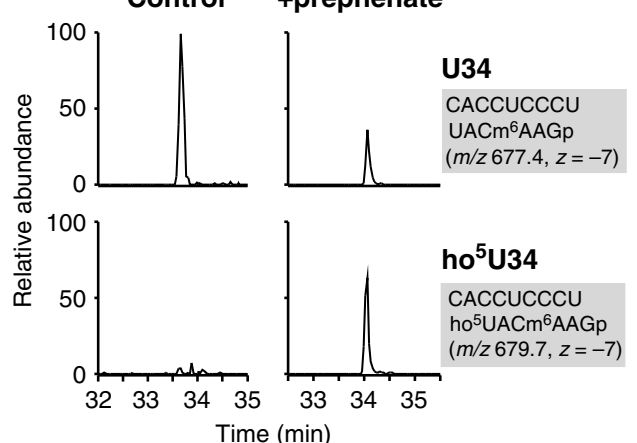

d

E162 H166 C170 C177 C193 C197

Peptidase U32

Peptidase U32 C

e

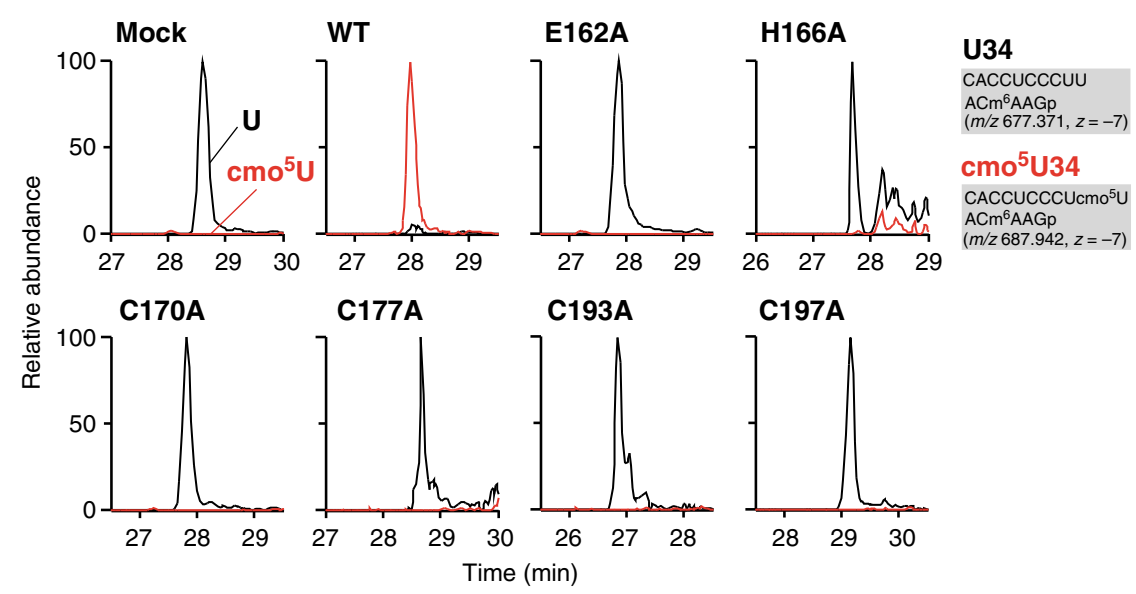

transformant (Fig. 5b). Furthermore, when prephenate was directly added to a culture medium of the quadruple-knockout strain, ho ${ }^{5} \mathrm{U} 34$ clearly appeared (Fig. $5 \mathrm{c}$ ). These results demonstrated that prephenate is required for ho ${ }^{5} \mathrm{U} 34$ formation.

To characterize the peptidase U32 domain of $\operatorname{trh} P$, we mutated each of six conserved residues in this domain (Fig. 5d, Supplementary Fig. 11) and examined their activities in vivo by complementation of the $\Delta t r h P / \Delta t r h O$ strain. Shotgun analyses revealed that $\mathrm{cmo}^{5} \mathrm{U} 34$ was fully restored by WT trhP, but not by any of the mutants examined in this study (Fig. 5e), indicating that the peptidase U32 domain plays a key role in $\operatorname{trh} P$-mediated tRNA hydroxylation.

Characterization of trhO-mediated tRNA hydroxylation. Given that $\mathrm{Fe}(\mathrm{II})$ - and 2-OG-dependent oxygenases use $\mathrm{O}_{2}$ as a 
Fig. 5 Characterization of trhP-mediated tRNA hydroxylation. a A shikimate pathway and related metabolism. Chemical structures of metabolites and the responsible genes (italicized) at each step are shown. Two or three genes at each step indicate a redundant pathway [e.g., prephenate is redundantly synthesized from chorismate mediated by phe $A(C M)$ and tyrA]. Black or gray arrows represent pathways indispensable or dispensable for trhP-mediated ho ${ }^{\mathrm{U} 34}$ formation, respectively (Supplementary Fig. 9). White arrows represent pathways not examined in this study. b Genetic complementation of ho ${ }^{5} 34$ formation. Mass-spectrometric shotgun analysis of total tRNAs obtained from the $E$. coli $\Delta p h e A / \Delta t y r A / \Delta c m o A / \Delta t r h O$ strain transformed with a control plasmid (left panels) or pMW-pheA(CM) (right panels). XICs show multiply charged negative ions of anticodon-containing fragments of tRNAVal1 with U34 (upper panels) and ho ${ }^{5} 34$ (lower panels). Sequence, $\mathrm{m} / \mathrm{z}$ value, and charge state of each fragment are shown on the right. c Metabolic complementation of ho ${ }^{5} \mathrm{U} 34$ formation. Mass-spectrometric shotgun analysis of total tRNAs obtained from the $E$. coli $\Delta p h e A / \Delta t y r A / \Delta c m o A / \Delta$ trhO strain cultured in the absence (left panels) or presence (right panels) of $1 \mathrm{mM}$ prephenate. XICs show multiply charged negative ions of anticodon-containing fragments of tRNAVal1 with U34 (upper panels) and ho ${ }^{5} \mathrm{U} 34$ (lower panels). Sequence, $\mathrm{m} / z$ value, and charge state of each fragment are shown on the right. d Domain organization of E. coli TrhP, which contains Peptidase_U32 (PF01136) and Peptidase_U32_C (PF16325) domains. Six residues in the Peptidase_U32 domain that are essential for TrhP-mediated hydroxylation are indicated. e Mutation study of trhP. Mass-spectrometric shotgun analysis of total tRNA in the E. coli $\triangle$ trhP strain transformed with plasmid-encoded trhP WT or mutants, as indicated. XICs show multiply charged negative ions of the anticodon-containing fragments of tRNA Val1 with U34 (black lines) and cmo $\mathrm{Cu}^{54}$ (red lines) in total tRNAs. Sequence, $\mathrm{m} / z$ value, and charge state of each fragment are shown on the right

substrate for hydroxylation, we next asked whether molecular oxygen is involved in ho ${ }^{5} \mathrm{U} 34$ formation. $\mathrm{cmo}^{5} \mathrm{U} 34$ formation is not affected in $E$. coli cultured under anaerobic conditions ${ }^{20}$, indicating that molecular oxygen is irrelevant to $\operatorname{trh} P$-mediated ho ${ }^{5} \mathrm{U} 34$ formation. To determine whether $\mathrm{O}_{2}$ is involved in trhOmediated ho ${ }^{5} \mathrm{U} 34$ formation, we cultured the E. coli $\Delta \operatorname{trh} P$ strain under aerobic and anaerobic conditions, and then monitored $\mathrm{cmo}^{5} \mathrm{U} 34$ formation by shotgun analysis. Very little $\mathrm{cmo}^{5} \mathrm{U} 34$ was detected in $\triangle$ trhP cells cultured under anaerobic conditions (Fig. 6a), whereas no reduction in $\mathrm{cmo}^{5} \mathrm{U} 34$ was observed in WT cells (Supplementary Fig. 12), implying that $\mathrm{O}_{2}$ is necessary for trhO-mediated ho ${ }^{5} \mathrm{U} 34$ formation. We then metabolically labeled ho ${ }^{5} \mathrm{U} 34$ using ${ }^{18} \mathrm{O}$-labeled $\mathrm{O}_{2}$. To accumulate ho ${ }^{5} \mathrm{U} 34$, we cultured the E. coli $\Delta t r h P / \triangle \mathrm{cmoB}$ strain in mixed gas containing $20 \%{ }^{18} \mathrm{O}_{2}$. Total RNA extracted from this culture was digested into nucleosides and subjected to LC/MS. We clearly detected a deprotonated ho ${ }^{5} \mathrm{U} 34$ nucleoside with molecular mass $(\mathrm{m} / \mathrm{z} 261)$ $2 \mathrm{Da}$ greater than that of the naturally occurring nucleoside (Fig. 6b). CID analysis of the nucleoside revealed that the ${ }^{18} \mathrm{O}$ atom was present in the base moiety of ${ }^{5}{ }^{5} \mathrm{U}$ (Supplementary Fig. 13). No oxygens in the uracil base were labeled with ${ }^{18} \mathrm{O}$ under the ${ }^{18} \mathrm{O}$-air condition (Supplementary Fig. 13), demonstrating that $\operatorname{trhO}$-mediated tRNA hydroxylation utilizes $\mathrm{O}_{2}$ as an oxygen atom donor.

Next, we generated recombinant E. coli TrhO and subjected it to biochemical characterization. Electrophoretic mobility shift assay (EMSA) revealed that TrhO interacted with tRNA ${ }^{\text {Ala1 }}$, but not with tRNA ${ }^{\text {Leu3 }}$ (Fig. 6c). This result is consistent with our observation that $\mathrm{cmo}^{5} \mathrm{U} 34$ of $\mathrm{tRNA}^{\mathrm{Leu} 3}$ is mainly synthesized via the $\operatorname{trh} P$-mediated pathway, whereas $\mathrm{mcmo}^{5} \mathrm{U} 34$ of tRNA ${ }^{\mathrm{Ala}}$ is redundantly synthesized by both the trhP- and trhO-mediated pathways. We then attempted to reconstitute ho ${ }^{5} \mathrm{U}$ in vitro, and successfully detected $\mathrm{ho}^{5} \mathrm{U}$ on tRNA ${ }^{\text {Serl }}$ in the presence of recombinant TrhO. When TrhO was present in excess, $75 \%$ of the tRNA had ho ${ }^{5} \mathrm{U}$ (Fig. 6d). CID analysis of the modified fragment confirmed that ho ${ }^{5} \mathrm{U}$ was formed at position 34 of the tRNA (Supplementary Fig. 14). This result demonstrated that TrhO is an RNA hydroxylase that can form ho ${ }^{5} \mathrm{U} 34$ on tRNA by utilizing $\mathrm{O}_{2}$ as an oxygen donor.

TrhO is a rhodanese family protein characterized by the CXGGXR motif ${ }^{49}$, with an active-site cysteine in a glycine-rich loop (Fig. 6e, Supplementary Fig. 15). The crystal structure of Legionella pneumophila Lpg2838, a TrhO homolog, was solved by structural genomics (Supplementary Fig. 16) ${ }^{50}$. In the rhodanese domain, the active-site loop structure with the CTGGIR sequence (positions 200-205 in E. coli numbering) is formed by hydrogen bonds between T201 and R205 (corresponding to T178 and R182 in Supplementary Fig. 16). To characterize this motif, we constructed a series of $E$. coli trhO mutants in which C200, T201, G202, G203, R205, or C206 was mutated to alanine, and then examined their activities in vivo by complementation of the $\Delta \operatorname{trhP} / \Delta \operatorname{trhO}$ strain. The level of $\mathrm{cmo}^{5} \mathrm{U} 34$ in tRNA ${ }^{\text {Vall }}$ was partially restored by WT trhO (Fig. 6f). For the trhO mutants, C200, T201, G203, and R205 were essential for trhO-mediated tRNA hydroxylation, whereas G202 and C206 were not (fig. 6f). In the TrhO structure, a positively charged $\beta$-sheet is present near the active-site loop (Supplementary Fig. 16), providing a surface capable of recognizing tRNAs. The trhO mutants $\mathrm{K} 112 \mathrm{~A}$ and R114A, which lack positively charged residues on the $\beta$-sheet surface, hardly rescued or did not rescue $\mathrm{cmo}^{5} \mathrm{U} 34$ formation, respectively (Fig. $6 \mathrm{f}$ ), suggesting that this surface is required for trhO-mediated tRNA hydroxylation.

\section{Discussion}

In this study, we identified two independent pathways, mediated by $\operatorname{trh} P$ and $\operatorname{trhO}$, involved in tRNA hydroxylation in the early steps of $(\mathrm{m}) \mathrm{cmo}^{5} \mathrm{U} 34$ formation. We confirmed that (m) $\mathrm{cmo}^{5} \mathrm{U} 34$ was completely converted to unmodified U34 in a $\Delta \operatorname{trh} P / \Delta t r h O$ strain. This finding enabled us to analyze the physiological roles of $(\mathrm{m}) \mathrm{cmo}^{5} \mathrm{U} 34$. This strain grew more slowly than a $\triangle c m o B$ strain, which has $h^{5} \mathrm{U} 34$, confirming the physiological importance of the $\mathrm{O} 5$ oxygen atom of $(\mathrm{m}) \mathrm{cmo}^{5} \mathrm{U} 34$. In addition, the $\Delta t r h P / \Delta t r h O$ strain exhibited severe growth defects and temperature-sensitive phenotypes when each of the tRNA genes (ser $\mathrm{U}, \mathrm{thr} W$, and proK) responsible for G-ending codons was simultaneously deleted. These genetic interactions strongly indicate that $(\mathrm{m}) \mathrm{cmo}^{5} \mathrm{U} 34$ plays a functional role in efficiently deciphering G-ending codons. The luciferase reporter assay revealed that decoding of UCG was significantly impaired in the $\Delta \operatorname{trhP} / \Delta \operatorname{trhO}$ strain relative to the $\triangle c m o B$ strain in the absence of tRNA $^{\text {Ser2 }}$, suggesting that the ho ${ }^{5} \mathrm{UGA}$ anticodon decodes the UCG codon more efficiently than the UGA anticodon. These observations demonstrate the direct involvement of the $\mathrm{O} 5$ oxygen of the $\mathrm{xo}^{5} \mathrm{U} 34$ modification in codon recognition in vivo.

According to the crystal structure of the ribosome 30 S subunit in complex with the anticodon-stem loop (ASL) of tRNA, $\mathrm{cmo}^{5} \mathrm{U}-\mathrm{G}$ pairing forms Watson-Crick geometry (Supplementary Fig. 17), which is more stable than U-G wobble geometry due to the stacking interaction with the neighboring base pair (i.e., the second letters of codon and anticodon) ${ }^{19}$. The O5 oxygen of $\mathrm{cmo}^{5} \mathrm{U} 34$ makes a hydrogen bond with 2' $\mathrm{OH}$ of U33 to prestructure the ASL, presumably reducing entropic cost to base pair with any codons. In addition, the O5 oxygen may induce keto-toenol tautomeric conversion of the uracil base to stabilize $\mathrm{cmo}^{5} \mathrm{U}$ G pairing in Watson-Crick geometry. Moreover, because (m) $\mathrm{cmo}^{5} \mathrm{U} 34$ decodes G-ending codons more efficiently than 
a

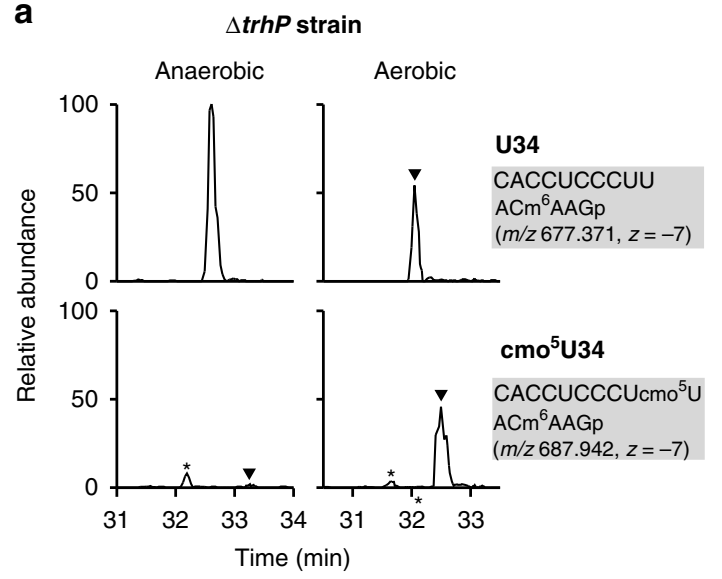

b

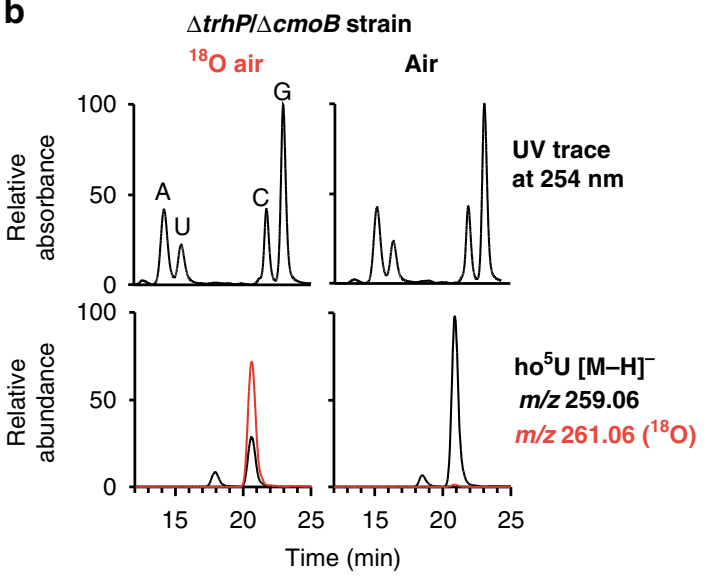

C
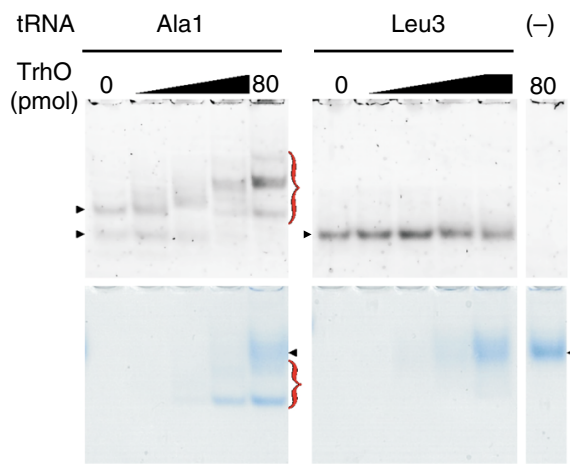

d
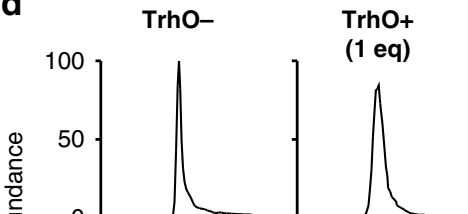

TrhO+

(10 eq)
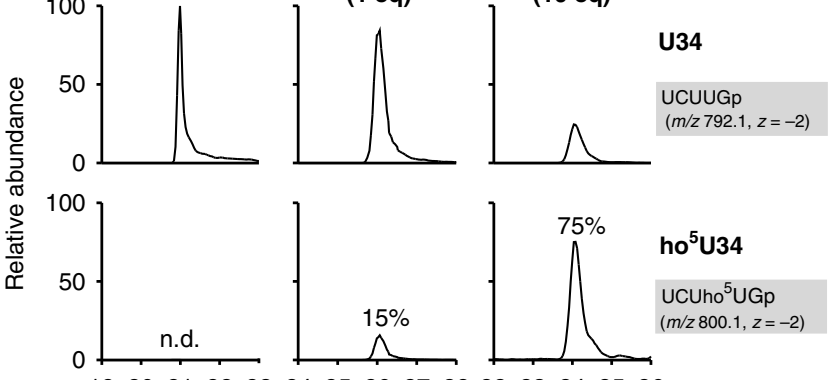

192021222324252627282223242526

Time (min)

e

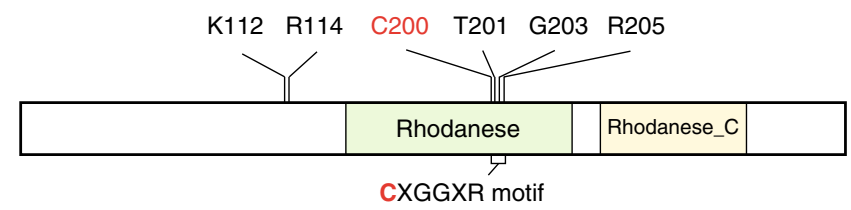

f
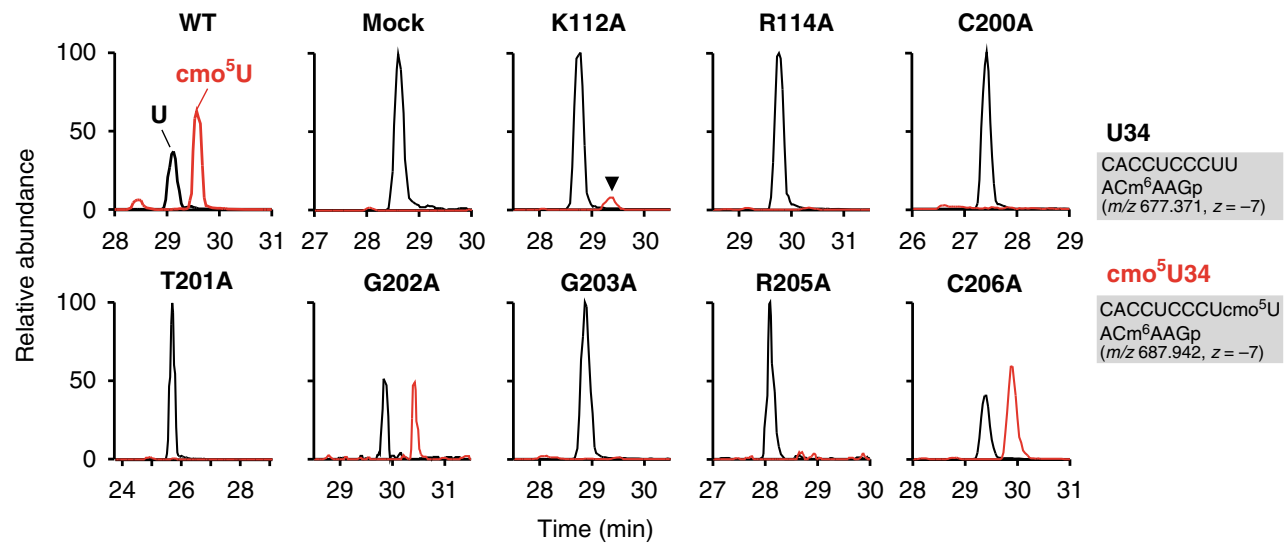

ho ${ }^{5} \mathrm{U} 34^{13,18}$, the carboxymethyl group and terminal methylation of $(\mathrm{m}) \mathrm{cmo}^{5} \mathrm{U} 34$ contribute further to efficient codon recognition. Structural analysis has shown that the carboxymethyl group of $\mathrm{cmo}^{5} \mathrm{U} 34$ forms a hydrogen bond with the $\mathrm{O} 4$ carbonyl oxygen of $\mathrm{U}$ in the first letter of the codon, implying that the $\mathrm{cmo}^{5} \mathrm{U}$ side chain is directly involved in codon recognition ${ }^{19}$. Because ho ${ }^{5} \mathrm{U} 34$ has a phenolic hydrogen, and the $\mathrm{pK}_{\mathrm{a}}$ value of $\mathrm{O} 5$ is $7.78^{51}$, ho ${ }^{5} \mathrm{U} 34$ is ionized to some extent under neutral $\mathrm{pH}$ conditions. Thus, the carboxymethylation of $\mathrm{cmo}^{5} \mathrm{U} 34$ and methylation of mo ${ }^{5} \mathrm{U} 34$ might confer efficient codon recognition by suppressing the ionization of $\mathrm{ho}^{5} \mathrm{U} 34$.
Our findings reveal that the TrhP-dependent pathway requires prephenate, whereas the TrhO-dependent pathway requires molecular oxygen. Thus, these two pathways are biochemically independent with respect to their requirement for metabolites. The existence of redundant and robust pathways for $\mathrm{ho}^{5} \mathrm{U}$ formation emphasizes that the $\mathrm{xo}^{5} \mathrm{U} 34$ modification is essential for bacteria to survive in a harsh environment. This is the unique instance of the RNA modification synthesized by two independent pathways in the same organism. According to phylogenetic distribution analysis in all domains of life (Supplementary Fig. 6), some organisms possess both trhP and trhO genes, whereas other 
Fig. 6 Characterization of trhO-mediated tRNA hydroxylation. a trhO-mediated $\mathrm{cmo}^{5} \mathrm{U}$ formation takes place under aerobic conditions. Mass-spectrometric shotgun analysis of total tRNAs obtained from E. coli $\Delta$ trhP strain cultured under anaerobic (left panels) or aerobic (right panels) conditions. XICs show negative ions of the anticodon-containing fragments of tRNAVal1 with U34 (upper panels) and $\mathrm{cmo}^{5} \mathrm{U} 34$ (lower panels). Arrowheads indicate target peaks, and asterisks indicate unspecific peaks. b Molecular $\mathrm{O}_{2}$ is the metabolic source of the hydroxyl group of ho ${ }^{5} \mathrm{U} 4$ generated by trhO. Mass-spectrometric nucleoside analyses of total RNAs obtained from the E. coli $\Delta t r h P / \Delta c m o B$ strain cultured in mixed gas with $20 \%{ }^{18} \mathrm{O}_{2}$ (left panels) or in normal air (right panels). UV traces at $254 \mathrm{~nm}$ (upper panels) and XICs (lower panels) of deprotonated ho5 $\mathrm{U}$ extracted from non-labeled (black line) or [ $\left.{ }^{18} \mathrm{O}\right]-$ labeled (red line) cells are shown. c TrhO interacts with tRNAAlar specifically. Electrophoretic mobility shift assay (EMSA) was performed to detect direct interaction

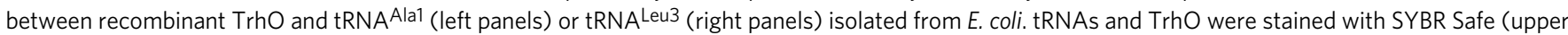
panels) and Coomassie brilliant blue (lower panels), respectively. TrhO-tRNA complexes are indicated by red traces. Arrowheads indicate unbound intact tRNAs and TrhO. Source data are provided as a Source Data file. $\mathbf{d}$ In vitro reconstitution of ho ${ }^{5} \mathrm{U}_{3} 4$ with recombinant TrhO. RNase $\mathrm{T}_{1}$ digests of $E$. coli tRNA ${ }^{\text {Ser } 1}$ transcripts $(10 \mathrm{pmol})$ incubated with $(10 \mathrm{pmol} ; 1 \mathrm{eq}$ or $100 \mathrm{pmol} ; 10 \mathrm{eq})$ or without TrhO are subjected to RNA-MS. XICs show doubly charged negative ions of the anticodon-containing fragments of tRNA transcript with U34 (upper panels) and ho $\mathrm{U}_{34}$ (lower panels). Frequencies of ho ${ }^{5} \mathrm{U} 34$ are indicated. e Domain organization of E. coli TrhO bearing Rhodanese (PF00581) and Rhodanese_C (PF12368) domains. The CXGGXR motif and six residues mutated in this study are indicated. $\mathbf{f}$ Mutation study of trhO. Mass-spectrometric shotgun analysis of total tRNAs in the $E$. coli $\Delta$ trhP/ $\Delta$ trhO strain transformed with plasmid-encoded trhO WT or mutants, as indicated. XICs show multiply charged negative ions of the anticodon-containing fragments of tRNAVal1 with U34 (black lines) and $\mathrm{cmo}^{5} \mathrm{U} 34$ (red lines) from total tRNA

organisms possess just one of them. Considering that anaerobes preceded aerobes in the early evolution on Earth, the trhP pathway might have been established in anaerobic bacteria before the trhO pathway arose, assuming that $\mathrm{x}^{5} \mathrm{U} 34$ was present in such ancestral organisms. Presumably, the $\operatorname{trhO}$ pathway was acquired by aerobic bacteria after the $\mathrm{O}_{2}$ concentration increased on Earth. The trhP pathway is required for anaerobic bacteria, whereas the $\operatorname{trh} P$ and $\operatorname{trhO}$ dual pathways are useful for organisms that live in both anaerobic and aerobic environments.

TrhP is a peptidase U32-containing protein. Phylogenetic analysis has shown that peptidase U32-containing proteins can be classified into 12 subfamilies (Supplementary Fig. 1) ${ }^{30}$. We showed previously that three of these families include the RlhA proteins (RlhA1, RlhA2a, and RlhA2b) responsible for $\mathrm{ho}^{5} \mathrm{C}$ formation in $23 \mathrm{~S} \mathrm{rRNA}^{30}$. It is plausible that other subfamilies are also involved in hydroxylation of RNA or other biomolecules. Clostridia species harbor a member of the PepU32\#1 family and trmR, but no homologs of $\operatorname{trhO}$ or $\operatorname{trh} P$, implying that $\mathrm{mo}^{5} \mathrm{U} 34$ is present and that PepU32\#1 family proteins are functional homologs of trhP in these species. Helicobacter pylori, a representative of the $\varepsilon$-proteobacteria, possesses a PepU32\#2 family protein (HP0169), $c m o A$, and $c m o B$, but no homologs of trhO or $\operatorname{trh} P$, indicating that $\mathrm{cmo}^{5} \mathrm{U} 34$ is present and suggesting that HP0169 is responsible for prephenate-dependent ho ${ }^{5} \mathrm{U} 34$ formation in this species. Intriguingly, HP0169 is required for gastric colonization by $H$. pylori ${ }^{52}$. Similarly, in Salmonella enterica, a $\operatorname{trh} P$ ortholog is associated with chicken macrophage infection ${ }^{53}$. Together, these findings suggest that $\mathrm{xo}^{5} \mathrm{U} 34$ contributes to bacterial infection and pathogenesis.

We found that prephenate is required for trhP-dependent ho ${ }^{5} \mathrm{U} 34$ formation. Given that prephenate is also a substrate for $\mathrm{cmo}^{5} \mathrm{U} 34$ formation mediated by $\mathrm{CmoA}$ and $\mathrm{CmoB}^{21}$, it is a critical metabolite involved in the entire pathway of $\mathrm{cmo}^{5} \mathrm{U} 34$ biogenesis. Prephenate is generated from chorismate, which in turn is a common precursor of multiple metabolites, including aromatic amino acids, quinones, folate, and siderophores ${ }^{47}$. Thus, $\mathrm{cmo}^{5} \mathrm{U} 34$ modification might be tightly associated with the shikimate pathway and biogenesis of aromatic amino acids. The frequency of $\mathrm{cmo}^{5} \mathrm{U} 34$ might be regulated by the cellular concentration of prephenate under some environmental stress conditions.

TrhP is a paralog of RlhA in the same family of peptidase U32containing proteins. RlhA is responsible for prephenatedependent ho ${ }^{5} \mathrm{C} 2501$ formation in E. coli $23 \mathrm{~S} \mathrm{rRNA}^{30}$, strongly implicating the involvement of the peptidase U32 motif in the C5-hydroxylation of pyrimidine base. Here, we showed that three conserved residues (E162, C170, and C177) in the motif of TrhP are essential for $\mathrm{ho}^{5} \mathrm{U} 34$ formation. Additionally, the corresponding residues (E161, C169, and C176) in RlhA were also required for $h^{5} \mathrm{C} 2501$ formation ${ }^{30}$, demonstrating that the peptidase U32 motif is directly involved in the hydroxylation of RNA. To date, we have no evidence that TrhP and RlhA directly catalyze the hydroxylation of RNA molecules. Given that RlhA is directly bound to the 50S subunit and its precursor in the cell, RlhA might be the hydroxylase responsible for $\mathrm{ho}^{5} \mathrm{C} 2501$ formation. By analogy, TrhP might be a hydroxylase for tRNA. Regarding the role of prephenate in ho ${ }^{5} \mathrm{U} 34$ formation, several possibilities should be considered. Prephenate might serve as an oxygen donor for $\mathrm{ho}^{5} \mathrm{U} 34$ formation, or alternatively as a coenzyme for the reaction. Moreover, we cannot exclude the possibility that unknown metabolites derived from prephenate are involved in ho ${ }^{5} \mathrm{U} 34$ formation. Further studies are necessary to elucidate the molecular mechanism underlying ho ${ }^{5} \mathrm{U} 34$ formation mediated by TrhP and prephenate.

trhO homologs are present in many aerobes and facultative anaerobes, but not in obligate anaerobes such as Bacteroides, Clostridium, and Bifidobacterium. trhO homologs are distributed in a wide range of bacteria, including $\alpha-, \beta$-, and $\gamma$-proteobacteria, Bacilli, actinobacteria, the FCB group, cyanobacteria, and a subset of phylum Tenericutes (Supplementary Fig. 6). Intriguingly, trhO homologs are also widely distributed in vertebrates and other eukaryotes. This finding suggests the presence of an $\mathrm{xo}^{5} \mathrm{U}$-type modification in eukaryotes.

We also showed that TrhO directly catalyzes oxygendependent ho ${ }^{5} \mathrm{U} 34$ formation. TrhO is related to rhodanese, which is involved in persulfide formation during detoxification of cyanide; however, the functions of most rhodanese family proteins remain unclear. In the context of RNA modifications, Tum1p is a rhodanese protein that mediates a persulfide sulfur for 2-thiouridine synthesis in eukaryotes ${ }^{38}$. Bacterial YbbB (also known as $\mathrm{MnmH}$ ) is another rhodanese family protein responsible for biogenesis of 2-selenouridine $\left(\mathrm{se}^{2} \mathrm{U}\right)^{54}$ and geranyl-2thioudirine $\left(\text { ges }^{2} \mathrm{U}\right)^{55}$. Mutation study of TrhO revealed that the active-site loop of the rhodanese domain is responsible for ho ${ }^{5} \mathrm{U} 34$ formation, suggesting that the rhodanese domain plays a critical role in hydroxylation of uracil base. Future studies should seek to clarify the mechanism by which rhodanese catalyzes this reaction.

We now have a complete picture of $\mathrm{xo}^{5} \mathrm{U} 34$ formation in bacteria (Fig. 7). In the first step, U34 is redundantly hydroxylated by TrhP and TrhO to form ho ${ }^{5} \mathrm{U} 34$ in tRNAs responsible for decoding NYN codons. TrhP requires prephenate as a metabolite for ho ${ }^{5} \mathrm{U} 34$ formation, whereas TrhO uses a molecular oxygen for this purpose under aerobic conditions. In E. coli, TrhP 


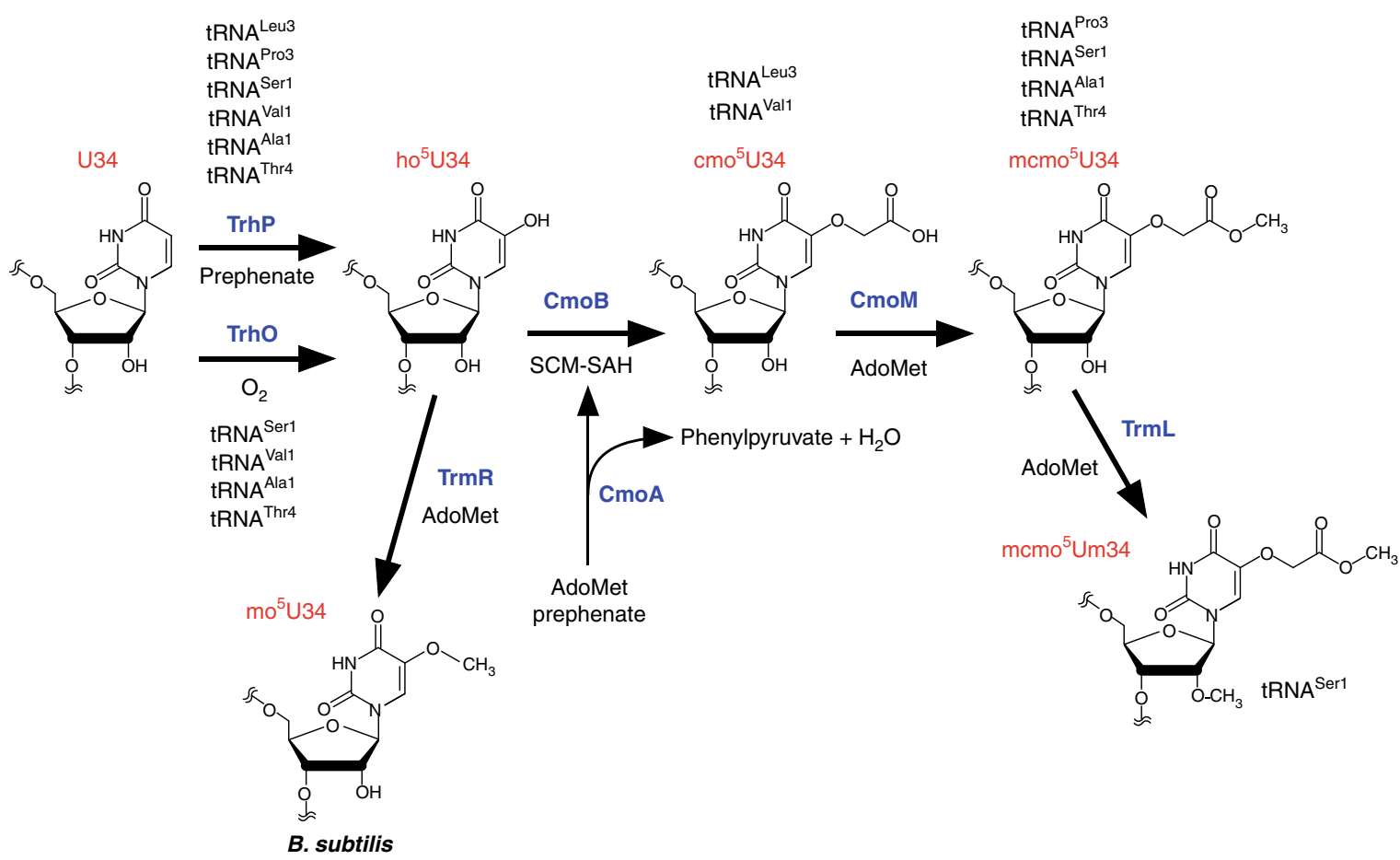

Fig. 7 Biogenesis of $\mathrm{mcmo}^{5} \mathrm{U} 34$ and derivatives. At the first step, U34 is redundantly hydroxylated by independent pathways mediated by TrhP and TrhO to form ho ${ }^{5} \mathrm{U} 34$ in tRNAs responsible for decoding NYN codons. TrhP requires prephenate as a metabolite for ho ${ }^{5} \mathrm{U}_{4}$ formation, whereas TrhO uses $\mathrm{O}_{2}$ to hydroxylate $\mathrm{U} 34$ to form ho $\mathrm{U}^{5} 4$ under aerobic conditions. CmoA synthesizes SCM-SAH from prephenate and AdoMet. CmoB uses SCM-SAH for carboxymethylation of ho $\mathrm{U}_{34}$ to yield $\mathrm{cmo}^{5} \mathrm{U} 34$. Four tRNAs (for Ala1, Ser1, Pro3, and Thr4) are further methylated by $\mathrm{CmoM}$ to yield mcmo $\mathrm{U}_{34}$. In Gram-positive bacteria, including B. subtilis, ho ${ }^{5} \mathrm{U} 34$ is methylated by $\operatorname{TrmR}$ to yield mo ${ }^{5} \mathrm{U} 34$

is involved in ho ${ }^{5} \mathrm{U} 34$ formation of all six tRNA species, but has a

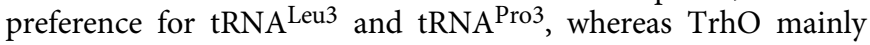
hydroxylates the other four species. CmoA employs prephenate and AdoMet to generate SCM-SAH, a metabolite used for carboxymethylation of ho5 ${ }^{5} 34$ to yield $\mathrm{cmo}^{5} \mathrm{U} 34$ catalyzed by CmoB. Four tRNAs (for Ala1, Ser1, Pro3, and Thr4) are further methylated by $\mathrm{CmoM}$ to yield $\mathrm{mcmo}^{5} \mathrm{U} 34 . \mathrm{mcmo}^{5} \mathrm{U} 34$ in tRNA $^{\text {Serl }}$ is partially methylated by TrmL to yield $\mathrm{mcmo}^{5} \mathrm{Um} 34$ as a minor modification. In Gram-positive bacteria, including $B$. subtilis, ho ${ }^{5} \mathrm{U} 34$ is methylated by TrmR to yield $\mathrm{mo}^{5} \mathrm{U} 34$ instead of $(\mathrm{m}) \mathrm{cmo}^{5} \mathrm{U} 34$.

\section{Methods}

Strains and media. A series of single-knockout strains of E. coli and their parent strain were obtained from the National BioResource Project (NBRP), National Institute of Genetics (NIG), Japan (Keio collection) ${ }^{56}$. Other knockout strains were generated by homologous recombination using $\lambda$-derived Red recombinase ${ }^{57}$ with the chloramphenicol-resistance $\left(\mathrm{Cm}^{\mathrm{R}}\right)$ or the kanamycin-resistance marker $\left(\operatorname{Kan}^{\mathrm{R}}\right)$; all strains were selected with the appropriate antibiotics $(20 \mu \mathrm{g}$ per $\mathrm{ml}$ chloramphenicol or $50 \mu \mathrm{g}$ per ml kanamycin). E. coli strains with multiple gene deletions were constructed by $\mathrm{P} 1$ transduction. The Kan ${ }^{\mathrm{R}}$ marker was removed by pCP20 transformation ${ }^{56}$. Genotyping of each construct was performed by colony PCR. A series of knockout strains [ $\Delta y r r O(\Delta t r h P 1):: \mathrm{Em}^{\mathrm{R}}, \Delta y r r N(\Delta t r h P 2):: \mathrm{Em}^{\mathrm{R}}$, and $\Delta y b f Q(\Delta t r h O):: \mathrm{Em}^{\mathrm{R}}$ ] and their parent strain [B. subtilis 168 MGNA-A001 $(\operatorname{trp} C 2)]$ were obtained from the NBRP, NIG, Japan ${ }^{58}$. To construct $\Delta y r r N / \Delta y r r O$, $\Delta y r r M$, and $\Delta y b f Q / \Delta y r r N / \Delta y r r O$ strains, the $\mathrm{Cm}^{\mathrm{R}}$ cassette amplified from pDLK2 (courtesy of Akiko Soma, Chiba Univ.) was flanked by the 5' and 3' regions ( $\sim 800$ bps) of the target genes by ligation PCR, followed by transformation and selection with $5 \mu \mathrm{g}$ per ml chloramphenicol. All constructs were confirmed by colony PCR. All primers and strains used in this study are listed in Supplementary Data 3 and Supplementary Table 2, respectively.

M9 minimal medium with $0.4 \%$ glucose or LB medium, as well as the corresponding solid media containing $1.5 \%$ agar, were used for growth analysis of E. coli. MOPS medium with 20 amino acids $(10 \mathrm{mM} \mathrm{Ser,} 0.8 \mathrm{mM}$ Ala/Gly/Leu, $0.6 \mathrm{mM}$ Gln/Glu/Val, 0.4 mM Arg/Asn/Ile/Lys/Phe/Pro/Thr, $0.2 \mathrm{mM}$ His/Met/Tyr, and $0.1 \mathrm{mM}$ Cys/Trp), five vitamins $(0.02 \mathrm{mM}$ thiamine hydrochloride, $0.02 \mathrm{mM}$ calcium pantothenate, $0.02 \mathrm{mM} 4$-aminobenzoic acid, $0.02 \mathrm{mM}$ 4-hydroxybenzoic acid, $0.02 \mathrm{mM}$ 2,3-dihydroxybenzoic acid), 0.4\% glucose, and appropriate antibiotics, in the presence or the absence of $1 \mathrm{mM}$ prephenate (Sigma-Aldrich, St. Louis, MO, USA), was used to determine the metabolite required for the $\operatorname{trh} P$ pathway.

Plasmid construction. For the genetic rescue study, CDSs of $\operatorname{trh} P, \operatorname{trhO}$, and pheA with their $200 \mathrm{bp}$ upstream sequences (including native promoter regions) were PCR-amplified from the E. coli BW25113 genome and cloned into pMW118 (Nippon Gene) to yield pMW-trhP, pMW-trhO, and pMW-pheA, respectively. pMW-pheA(CM), which lacks prephenate dehydratase activity due to the T278A mutation $^{48}$, and a series of point mutants of pMW-trhP and pMW-trhO were constructed by QuikChange site-directed mutagenesis (Agilent Technology). For expression vectors of TrhO (YceA) and TrmR (YrrM), CDSs of trhO and trmR were PCR-amplified from genomic DNAs of E. coli BW25113 and B. subtilis 168, respectively, and cloned into pET21b (Novagen) to yield pET-trhO and pET-trmR. All constructs were confirmed by Sanger sequencing. All primers used in this study are listed in Supplementary Data 3.

RNA extraction and tRNA isolation. Total RNA from each E. coli strain was extracted by phenol under acidic conditions ${ }^{35}$. The cells suspended in $1 \times$ TE buffer [10 mM Tris (pH 8.0), $1 \mathrm{mM}$ EDTA] was mixed with an equal volume of watersaturated phenol, followed by freeze and thaw twice and vigorous mixing for one hour at room temperature. The aqueous phase was separated by centrifugation, transferred to a new tube, washed with chloroform, and further purified using TRIzol reagent (Thermo Fisher Scientific, Waltham, MA, USA) and chloroform. RNA was recovered by 2-propanol precipitation. Individual tRNAs were isolated by reciprocal circulating chromatography (RCC) ${ }^{42}$ using a series of DNA probes ${ }^{13}$ (Supplementary Data 3). For RNA-MS shotgun analyses ${ }^{13}$, E. coli strains were cultured overnight, harvested, and resuspended in TE buffer to extract total RNA by TRIzol. The small RNA fraction was obtained as follows ${ }^{13} .50-250 \mu \mathrm{g}$ of total RNA in $800 \mu \mathrm{l}$ of $3 \mathrm{M} \mathrm{NH}_{4} \mathrm{OAc}$ ( $\mathrm{pH} 5.3$ ) was mixed with $640 \mu \mathrm{l}$ (0.8 volume) of isopropanol at room temperature and centrifuged at $20,400 \times \mathrm{g}$ for $10 \mathrm{~min}$ to precipitate long RNAs including rRNAs. The smaller RNA fraction was precipitated with ethanol from the supernatant. For RNA-MS shotgun analyses of B. subtilis tRNA modifications, the harvested cells were treated with $1 \mathrm{mg}$ per $\mathrm{ml}$ lysozyme for $10 \mathrm{~min}$ on ice, and then subjected to TRIzol treatment to extract total RNA.

Mass spectrometry of tRNA modifications. Liquid chromatography-mass spectrometry (LC/MS) analyses of tRNA modification were conducted as 
follows ${ }^{13,35}$. For RNA fragment analyses of individual tRNAs and shotgun analyses, $1.25 \mathrm{pmol}$ of tRNA or $50 \mathrm{ng}$ of the small RNA fraction was digested with 50 units RNase $\mathrm{T}_{1}$ (Thermo Scientific) in $20 \mathrm{mM} \mathrm{NH}_{4} \mathrm{OAc}$ ( $\mathrm{pH}$ 5.3), followed by addition of an equal volume of $0.1 \mathrm{M}$ triethylamine acetate (TEAA; $\mathrm{pH}$ 7.0). The RNase $\mathrm{T}_{1}$ digests were subjected to the trap column for desalting and chromatographed by

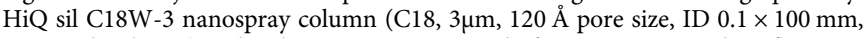

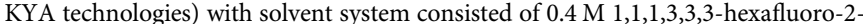
propanol (HFIP) (pH 7.0) (solvent A) and 0.4 M HFIP (pH 7.0) in 50\% methanol (solvent B) at a flow rate of $300 \mathrm{nl}$ per min with a linear gradient of $5-100 \% \mathrm{~B}$ solvent over $35 \mathrm{~min}$ with a splitless nano HPLC system (DiNa, KYA Technologies). The eluent was ionized by ESI source and introduced into an ion trap-orbitrap hybrid mass spectrometer (LTQ Orbitrap XL, Thermo Fisher Scientific). Ions were scanned with a negative polarity mode over an $\mathrm{m} / \mathrm{z}$ range of 600-2000 throughout the separation. XICs were plotted according to the theoretical $\mathrm{m} / \mathrm{z}$ of each fragment (Supplementary Table 1). LC/MS nucleoside analysis was performed using Q Exactive Hybrid Quadrupole-Orbitrap Mass Spectrometer (Thermo Fisher Scientific) equipped with a Dionex UltiMate 3000 LC System (Thermo Fisher Scientific) essentially as described ${ }^{13,59}$. Twenty micrograms of the small RNA fraction were digested at $37^{\circ} \mathrm{C}$ for $3 \mathrm{~h}$ in $60 \mu \mathrm{l}$ of solution containing $20 \mathrm{mM}$ trimethylamine- $\mathrm{HCl}$ (TMA-HCl) (pH 7.0), $0.05 \mathrm{U}$ of nuclease $\mathrm{P} 1$, and $0.1 \mathrm{U}$ of BAP. The digests mixed with acetonitrile (f.c. $90 \%)$ were chromatographed by ZIC-cHILIC column $(3 \mu \mathrm{m}$ particle size, $2.1 \times 150 \mathrm{~mm}$, Merck Millipore) with a guard column with the same resin $(2.1 \times 20 \mathrm{~mm}$, Merck Millipore $)$ using a solvent system consisted of $5 \mathrm{mM}$ $\mathrm{NH}_{4} \mathrm{OAc}$ (pH 5.3) (solvent A) and acetonitrile (solvent B) at a flow rate of $100 \mu \mathrm{l}$ $\mathrm{min}^{-1}$ in a multistep linear gradient; $90-40 \% \mathrm{~B}$ from 0 to $30 \mathrm{~min}, 40 \% \mathrm{~B}$ for $10 \mathrm{~min}$, and then initialized to $90 \% \mathrm{~B}$. The eluent was directly introduced into the ESI source and analyzed by mass spectrometer. Deprotonated nucleosides were scanned in a negative polarity mode over a $\mathrm{m} / \mathrm{z}$ range of $110-700$ throughout separation. Data were analyzed using Xcalibur software (Thermo Fisher Scientific).

Basically, in negative mode of ESI, ionization efficiencies of the RNA fragments bearing the same sequence but different modification do not differ largely, because ESI ionization relies mainly on numbers of phosphate groups, not on type of base modifications ${ }^{60}$. Thus, we relatively quantified modification frequencies of RNA fragments with different chemical structures from their intensities of XICs.

Luciferase reporter assay. The dual-luciferase reporter assay ${ }^{13}$ was performed as follows: knockout strains were transformed with pBAD-RFlucGCG, pBAD-RFlucUCG, or pBAD-RFlucGG. Each transformant was pre-cultivated at $37^{\circ} \mathrm{C}$ in $2 \mathrm{ml}$ LB medium containing $100 \mu \mathrm{g}$ per $\mathrm{ml}$ ampicillin overnight. The preculture $(1 \mathrm{ml})$ was inoculated to $2 \mathrm{ml}$ of LB medium containing $100 \mu \mathrm{g}$ per ml ampicillin and $100 \mu \mathrm{M}$ arabinose to induce expression of the reporter. When the $\mathrm{OD}_{600}$ reached to $0.3-0.7,1 \mathrm{ml}$ aliquot was centrifuged, and the pelleted cells were resuspended in $200 \mu \mathrm{l}$ of lysis buffer [10 mM HEPES-KOH (pH 7.5), $100 \mathrm{mM} \mathrm{NaCl}, 10 \mathrm{mM} \mathrm{MgCl}_{2}$, $7 \mathrm{mM}$ 2-mercaptoethanol, $400 \mu \mathrm{g}$ per $\mathrm{ml}$ lysozyme]. Cell lysates were prepared by the freeze-thaw and cleared by centrifugation. The luciferase reporter assay was performed with $5 \mu \mathrm{l}$ lysate using GloMax ${ }^{\mathrm{ma}} 96$ Microplate Luminometer (Promega). The Fluc luminescence signal was normalized against the Rluc signal.

Anaerobic cultivation. WT and $\Delta t r h P$ strains were precultured in a BioShaker G.BR-200 (TAITEC) at $37^{\circ} \mathrm{C}$ with rotation at $60 \mathrm{rpm}$ for $24 \mathrm{~h}$ in $10 \mathrm{ml}$ of degassed LB medium in a $10 \mathrm{~cm}$ dish doubly packed in Ziploc (Asahi-Kasei, Japan) with one bag of AnaeroPack-Anaero (Mitsubishi Gas Chemical, Japan) and an oxygen indicator (OXY-1, JIKCO). The preculture $(100 \mu \mathrm{l})$ was inoculated into $10 \mathrm{ml}$ of degassed LB medium, sealed with an AnaeroPack-Anaero, incubated at room temperature for $1 \mathrm{~h}$ to deoxidize completely, and then cultivated at $37^{\circ} \mathrm{C}$ overnight at $60 \mathrm{rpm}$.

Metabolic labeling analysis using ${ }^{18} \mathrm{O}_{\mathbf{2}} .{ }^{18} \mathrm{O}$-containing mixed gas $\left[20 \%{ }^{18} \mathrm{O}_{2}\right.$ $\left(97.5 \%{ }^{18} \mathrm{O}_{2}, 1 \%{ }^{17} \mathrm{O}_{2}, 1.5 \%{ }^{16} \mathrm{O}_{2}\right), 80 \% \mathrm{~N}_{2}$ ] was obtained commercially (Tatsuoka, Japan). The $\Delta c m o B / \Delta t r h P$ stain was precultured at $37^{\circ} \mathrm{C}$ overnight in $\mathrm{LB}$ medium containing $50 \mu \mathrm{g}$ per $\mathrm{ml}$ kanamycin. The preculture $(1 \mathrm{ml})$ was inoculated into $100 \mathrm{ml}$ of degassed LB medium containing $1 \mathrm{mM}$ uridine and $50 \mu \mathrm{g} / \mathrm{ml}$ kanamycin packed in a PVDF air-sampling bag (As One, Japan). Inside air was carefully removed, and then replaced once with $\mathrm{N}_{2}$ and twice with ${ }^{18} \mathrm{O}_{2}$ mixed gas. The bag was capped and sealed with Parafilm (Bemis), and then cultured at $37^{\circ} \mathrm{C}$ for $24 \mathrm{~h}$ at $100 \mathrm{rpm}$ in a BioShaker G.BR-200 (TAITEC). Total RNA was extracted from the culture, digested into nucleosides, and analyzed by LC/MS as described above.

Preparation of recombinant protein. E. coli BL21(DE3) transformed with pET trhO was cultured at $37^{\circ} \mathrm{C}$ until $\mathrm{OD}_{600}$ reached $\sim 0.7$, supplemented with $0.4 \%$ lactose, and further cultured at $16^{\circ} \mathrm{C}$ for $32 \mathrm{~h}$. The E. coli Rosetta(DE3) transformed with pET-trmR was cultured at $37^{\circ} \mathrm{C}$ until $\mathrm{OD}_{600}$ reached $\sim 0.7$, supplemented with $100 \mu \mathrm{M}$ IPTG, and further cultivated at $37^{\circ} \mathrm{C}$ for $4 \mathrm{~h}$ to induce overexpression. Cells were sonicated in lysis buffer for TrhO [50 mM HEPES-KOH (pH 7.5), $300 \mathrm{mM} \mathrm{KCl}, 10 \mathrm{mM} \mathrm{MgCl} 2,1 \mathrm{mM}$ dithiothreitol (DTT), and $0.2 \mathrm{mM}$ PMSF] or the lysis buffer for TrmR [50 mM HEPES-KOH (pH 7.5), $100 \mathrm{mM} \mathrm{KCl}$, $10 \mathrm{mM} \mathrm{MgCl}, 1 \mathrm{mM}$ dithiothreitol (DTT), and $0.2 \mathrm{mM}$ PMSF]. The recombinant proteins TrhO and TrmR were purified using a HisTrap column (GE Healthcare) with a linear gradient of imidazole (0-500 mM for TrhO, 25-500 mM for TrmR).
Purified protein was dialyzed in the individual lysis buffer, supplemented with glycerol to a final concentration of $30 \%$, and stored at $-20^{\circ} \mathrm{C}$.

In vitro reconstitution of tRNA modification. For in vitro ho ${ }^{5} \mathrm{U}$ formation by TrhO, tRNA ${ }^{\text {Serl }}$ transcript $(10 \mathrm{pmol})$ and recombinant TrhO (10 or $\left.100 \mathrm{pmol}\right)$ were incubated at $37^{\circ} \mathrm{C}$ for $1 \mathrm{~h}$ in a reaction mixture $(10 \mu \mathrm{l})$ containing $25 \mathrm{mM}$ Tris- $\mathrm{HCl}$ (pH 7.0), $300 \mathrm{mM} \mathrm{NaCl}, 1 \mathrm{mM} \mathrm{MgCl}$, and $10 \mathrm{mM}$ 2-mercaptoethanol. The tRNA was extracted with acidic phenol/chloroform and precipitated with ethanol, followed by RNase $\mathrm{T}_{1}$ digestion and RNA-MS analysis as described above.

In vitro methylation of ho ${ }^{5} \mathrm{U}$ by TrmR was performed essentially as described ${ }^{13}$ E. coli tRNA Thr4 bearing ho ${ }^{5} \mathrm{U} 34$ was isolated from the $\triangle c m o B$ strain. The reaction mixture $(10 \mu \mathrm{l})$ containing $10 \mathrm{pmol}$ of tRNA ${ }^{\text {Thr }} 4,20 \mathrm{pmol}$ of TrmR, $50 \mathrm{mM}$ HEPES-KOH (pH 7.5), $100 \mathrm{mM} \mathrm{KCl}, 10 \mathrm{mM} \mathrm{MgCl}_{2}$, and $7 \mathrm{mM} 2$-mercaptoethanol was incubated at $37^{\circ} \mathrm{C}$ for $1 \mathrm{~h}$ in the presence or absence of $1 \mathrm{mM}$ AdoMet.

Electrophoresis mobility shift assay. EMSA was performed essentially as described ${ }^{34}$. Recombinant $\operatorname{TrhO}(0,10,20,40$, or $80 \mathrm{pmol})$ and in vitro transcribed tRNA ${ }^{\text {Alal }}$ or tRNA teu3 $^{\text {Leu }}\left(20 \mathrm{pmol}\right.$ each) were incubated at $37^{\circ} \mathrm{C}$ for $1 \mathrm{~h}$ in $10 \mu \mathrm{l}$ of reaction mixture [ $50 \mathrm{mM}$ HEPES- $\mathrm{KOH}(\mathrm{pH} 7.5), 5 \mathrm{mM} \mathrm{Mg}(\mathrm{OAc})_{2}, 100 \mathrm{mM} \mathrm{KCl}$, $1 \mathrm{mM}$ spermine, $1 \mathrm{mM}$ DTT]. The mixtures were electrophoresed in $6 \%$ native polyacrylamide gel with running buffer [50 mM HEPES-KOH ( $\mathrm{pH}$ 7.5), $5 \mathrm{mM} \mathrm{Mg}$ $(\mathrm{OAc})_{2}$, and $1 \mathrm{mM} \mathrm{DTT]}$ in cold room. The gel was first stained with SYBR Safe (Thermo Fisher Scientific) to detect tRNA and then with Coomassie brilliant blue (Nacalai Tesque) to detect protein.

Comparative genomics. The comparative genomics approach used to identify the $\operatorname{trhO}(y c e A)$ gene was performed with the IMG database ${ }^{61}$. The gene occurrence profile was used to select seven organisms in which $c m o B A$ or $y r r M$ homologs were present and $\operatorname{trh} P($ yegQ) or trhP1/trhP2 homologs were absent: Ehrlichia canis str Jake, Erwinia pyrifoliae DSM12163, Alcanivorax borkumensis SK2, Candidatus Phytoplasma asteris onion yellows OY-M, Pontibacter actiniarum sp. BAB1700, Dactylococcopsis salina PCC 8305, and Psychrobacter arcticus 273-4. Using the phylogenic profiler, $141 \mathrm{E}$. coli genes that are conserved in these seven organisms and B. subtilis were identified. According to the UniProt gene annotation, seven uncharacterized genes were picked as candidates.

Phylogenetic analysis. The phylogenetic tree of peptidase U32 (Supplementary Fig. 1) was generated as described ${ }^{30}$. Species names matched to proteins were retrieved from UniProt. The occurrence profiles of $\operatorname{trhO}, \operatorname{trh} P, \operatorname{trh} P 1, \operatorname{trh} P 2, \mathrm{cmoA}$ $c m o B$, trmR, and $c m o M$ homologs (Supplementary Fig. 6) were retrieved from $\mathrm{GTOP}^{62}$ or the Interpro database ${ }^{63}$. To generate the phylogenetic tree, 584 organisms that are registered in the databases we used, i.e., species listed in GTOP, phyloT, and Pfam, were selected.

Reporting summary. Further information on research design is available in the Nature Research Reporting Summary linked to this article.

\section{Data availability}

A reporting summary for this Article is available as a Supplementary Information file. The source data for graphs and gels are provided as a Source Data file. All data is available from the corresponding author upon reasonable request.

Received: 9 November 2018 Accepted: 30 May 2019

Published online: 28 June 2019

\section{References}

1. Boccaletto, P. et al. MODOMICS: a database of RNA modification pathways. 2017 update. Nucleic Acids Res. 46, D303-D307 (2018).

2. Bjork, G. R. \& Hagervall, T. G. Transfer RNA modification: presence, synthesis, and function. EcoSal Plus 6, 1-68, https://doi.org/10.1128/ ecosalplus.ESP-0007-2013 (2014).

3. Suzuki, T. in Fine-Tuning of RNA Functions by Modification and Editing, Vol. 12 (ed. Grosjean, H.) 23-69 (Springer-Verlag Berlin and Heidelberg GmbH \& Co. KG, 2005).

4. Curran, J. F. Modified nucleosides in translation 493-516. (ASM press, Washington, DC, 1998)

5. Crick, F. H. Codon-anticodon pairing: the wobble hypothesis. J. Mol. Biol. 19, 548-555 (1966).

6. Barrell, B. G. et al. Different pattern of codon recognition by mammalian mitochondrial tRNAs. Proc. Natl Acad. Sci. USA 77, 3164-3166 (1980).

7. Inagaki, Y. et al. Translation of synonymous codons in family boxes by Mycoplasma capricolum tRNAs with unmodified uridine or adenosine at the first anticodon position. J. Mol. Biol. 251, 486-492 (1995). 
8. Suzuki, T., Nagao, A. \& Suzuki, T. Human mitochondrial tRNAs: biogenesis, function, structural aspects, and diseases. Annu Rev. Genet 45, 299-329 (2011).

9. Yokoyama, S. et al. Molecular mechanism of codon recognition by tRNA species with modified uridine in the first position of the anticodon. Proc. Natl Acad. Sci. USA 82, 4905-4909 (1985).

10. Kurata, S. et al. Modified uridines with C5-methylene substituents at the first position of the tRNA anticodon stabilize U.G wobble pairing during decoding. J. Biol. Chem. 283, 18801-18811 (2008).

11. Kirino, Y. et al. Codon-specific translational defect caused by a wobble modification deficiency in mutant tRNA from a human mitochondrial disease. Proc. Natl. Acad. Sci. USA 101, 15070-15075 (2004).

12. Murao, K., Saneyoshi, M., Harada, F. \& Nishimura, S. Uridin-5-oxy acetic acid: a new minor constituent from $E$. coli valine transfer RNA I. Biochem Biophys. Res Commun. 38, 657-662 (1970).

13. Sakai, Y., Miyauchi, K., Kimura, S. \& Suzuki, T. Biogenesis and growth phasedependent alteration of 5-methoxycarbonylmethoxyuridine in tRNA anticodons. Nucl. Acid Res 44, 509-523 (2016).

14. Murao, K., Hasegawa, T. \& Ishikura, H. 5-methoxyuridine: a new minor constituent located in the first position of the anticodon of tRNAAla tRNAThr, and tRNAVal from Bacillus subtilis. Nucleic Acids Res 3, 2851-2860 (1976).

15. Takai, K., Takaku, H. \& Yokoyama, S. Codon-reading specificity of an unmodified form of Escherichia coli tRNA1Ser in cell-free protein synthesis. Nucleic Acids Res. 24, 2894-2899 (1996).

16. Yokoyama, S. \& Nishimura, S. in tRNA: Structure, Biosynthesis, and Function (ed. Soll, D. R., U. L.) 207-224 (American Society for Microbiology, Washington, D.C., 1995).

17. Samuelsson, T. et al. Aberrations of the classic codon reading scheme during protein synthesis in vitro. J. Biol. Chem. 255, 4583-4588 (1980).

18. Nasvall, S. J., Chen, P. \& Bjork, G. R. The wobble hypothesis revisited: Uridine-5-oxyacetic acid is critical for reading of G-ending codons. RNA 13, 2151-2164 (2007).

19. Weixlbaumer, A. et al. Mechanism for expanding the decoding capacity of transfer RNAs by modification of uridines. Nat. Struct. Mol. Biol. 14, 498-502 (2007).

20. Hagervall, T. G., Jönsson, Y. H., Edmonds, C. G., McCloskey, J. A. \& Bjork, G. R. Chorismic acid, a key metabolite in modification of tRNA. J. Bacteriol. 172, 252-259 (1990).

21. Kim, J. et al. Structure-guided discovery of the metabolite carboxy-SAM that modulates tRNA function. Nature 498, 123-126 (2013).

22. Byrne, R. T., Whelan, F., Aller, P. \& Bird, L. E. S-Adenosyl-S-carboxymethylL-homocysteine: a novel cofactor found in the putative tRNA-modifying enzyme CmoA. Acta Crystallogr. Sect. D. Biol. Crystallogr. D69, 1090-1098 (2013).

23. Noma, A. et al. Expanding role of the jumonji $\mathrm{C}$ domain as an RNA hydroxylase. J. Biol. Chem. 285, 34503-34507 (2010).

24. Kawarada, L. et al. ALKBH1 is an RNA dioxygenase responsible for cytoplasmic and mitochondrial tRNA modifications. Nucl. Acid Res 45 7401-7415 (2017).

25. Nagao, A. et al. Hydroxylation of a conserved tRNA modification establishes non-universal genetic code in echinoderm mitochondria. Nat. Struct. Mol. Biol. 24, 778-782 (2017).

26. Liu, F. et al. ALKBH1-mediated tRNA demethylation regulates translation. Cell 167, 1897 (2016).

27. Zheng, G. et al. ALKBH5 is a mammalian RNA demethylase that impacts RNA metabolism and mouse fertility. Mol. Cell 49, 18-29 (2013).

28. Delatte, B. et al. RNA biochemistry. Transcriptome-wide distribution and function of RNA hydroxymethylcytosine. Science 351, 282-285 (2016).

29. Ploumakis, A. \& Coleman, M. L. OH, the places you'll go! hydroxylation, gene expression, and cancer. Mol. Cell 58, 729-741 (2015).

30. Kimura, S., Sakai, Y., Ishiguro, K. \& Suzuki, T. Biogenesis and irondependency of ribosomal RNA hydroxylation. Nucl. Acid Res 45, 1-14 (2017).

31. Suzuki, T., Ikeuchi, Y., Noma, A., Suzuki, T. \& Sakaguchi, Y. Mass spectrometric identification and characterization of RNA-modifying enzymes. Meth. Enzym. 425, 211-229 (2007).

32. Ikeuchi, Y., Kitahara, K. \& Suzuki, T. The RNA acetyltransferase driven by ATP hydrolysis synthesizes N4-acetylcytidine of tRNA anticodon. EMBO J. 27, 2194-2203 (2008).

33. Ikeuchi, Y., Shigi, N., Kato, J., Nishimura, A. \& Suzuki, T. Mechanistic insights into sulfur relay by multiple sulfur mediators involved in thiouridine biosynthesis at tRNA wobble positions. Mol. Cell 21, 97-108 (2006).

34. Kimura, S. et al. Discovery of the beta-barrel-type RNA methyltransferase responsible for $N^{6}$-methylation of $N^{6}$-threonylcarbamoyladenosine in tRNAs. Nucleic Acids Res 42, 9350-9365 (2014).

35. Miyauchi, K., Kimura, S. \& Suzuki, T. A cyclic form of $N^{6}$ threonylcarbamoyladenosine as a widely distributed tRNA hypermodification. Nat. Chem. Biol. 9, 105-111 (2013).
36. Noma, A., Kirino, Y., Ikeuchi, Y. \& Suzuki, T. Biosynthesis of wybutosine, a hyper-modified nucleoside in eukaryotic phenylalanine tRNA. EMBO J. 25, 2142-2154 (2006)

37. Noma, A. et al. Actin-binding protein ABP140 is a methyltransferase for 3methylcytidine at position 32 of tRNAs in Saccharomyces cerevisiae. RNA 17, 1111-1119 (2011)

38. Noma, A., Sakaguchi, Y. \& Suzuki, T. Mechanistic characterization of the sulfur-relay system for eukaryotic 2-thiouridine biogenesis at tRNA wobble positions. Nucleic Acids Res 37, 1335-1352 (2009).

39. Soma, A. et al. An RNA-modifying enzyme that governs both the codon and amino acid specificities of isoleucine tRNA. Mol. Cell 12, 689-698 (2003).

40. Kimura, S. \& Suzuki, T. Fine-tuning of the ribosomal decoding center by conserved methyl-modifications in the Escherichia coli 16S rRNA. Nucleic Acids Res. 38, 1341-1352 (2010).

41. Kimura, S. et al. Base methylations in the double-stranded RNA by a fused methyltransferase bearing unwinding activity. Nucleic Acids Res. 40 , 4071-4085 (2012).

42. Miyauchi, K., Ohara, T. \& Suzuki, T. Automated parallel isolation of multiple species of non-coding RNAs by the reciprocal circulating chromatography method. Nucl. Acid Res 35, e24-e24 (2007).

43. Murao, K., Ishikura, H., Albani, M. \& Kersten, H. On the biosynthesis of 5 methoxyuridine and uridine-5-oxyacetic acid in specific procaryotic transfer RNAs. Nucleic Acids Res 5, 1273-1281 (1978).

44. Ryu, H., Grove, T. L., Almo, S. C. \& Kim, J. Identification of a novel tRNA wobble uridine modifying activity in the biosynthesis of 5-methoxyuridine. Nucleic Acids Res. 46, 9160-9169 (2018).

45. Curran, J. F. Analysis of effects of tRNA:message stability on frameshift frequency at the Escherichia coli RF2 programmed frameshift site. Nucleic Acids Res. 21, 1837-1843 (1993).

46. Bjork, G. R. A novel link between the biosynthesis of aromatic amino acids and transfer RNA modification in Escherichia coli. J. Mol. Biol. 140, 391-410 (1980).

47. Kanehisa, M. et al. Data, information, knowledge and principle: back to metabolism in KEGG. Nucl. Acid Res 42, D199-D205 (2014).

48. Zhang, S., Wilson, D. B. \& Ganem, B. Probing the catalytic mechanism of prephenate dehydratase by site-directed mutagenesis of the Escherichia coli $\mathrm{P}$ protein dehydratase domain. Biochemistry 39, 4722-4728 (2000).

49. Bordo, D. \& Bork, P. The rhodanese/Cdc25 phosphatase superfamily. Sequence-structure-function relations. in EMBO Rep. 3, 741-746 (2002).

50. Kuzin, A. et al. Three dimensional structure of the double mutant of UPF0176 protein $\operatorname{lpg} 2838$ from Legionella pneumophila at the resolution $1.8 \mathrm{~A}$, Northeast Structural Genomics Consortium (NESG) Target LgR82. (2012)

51. La Francois, C. J., Jang, Y. H., Cagin, T., Goddard, W. A. \& Sowers, L. C. Conformation and proton configuration of pyrimidine deoxynucleoside oxidation damage products in water. Chem. Res. Toxicol. 13, 462-470 (2000)

52. Kavermann, H. et al. Identification and characterization of Helicobacter pylor genes essential for gastric colonization. J. Exp. Med 197, 813-822 (2003)

53. Zhao, Y. et al. Identification of genes affecting Salmonella enterica serovar enteritidis infection of chicken macrophages. Infect. Immun. 70, 5319-5321 (2002)

54. Wolfe, M. D. et al. Functional diversity of the rhodanese homology domain: the Escherichia coli ybbB gene encodes a selenophosphate-dependent tRNA 2selenouridine synthase. J. Biol. Chem. 279, 1801-1809 (2004).

55. Dumelin, C. E., Chen, Y., Leconte, A. M., Chen, Y. G. \& Liu, D. R. Discovery and biological characterization of geranylated RNA in bacteria. Nat. Chem. Biol. 8, 913-919 (2012)

56. Baba, T. et al. Construction of Escherichia coli K-12 in-frame, single-gene knockout mutants: the Keio collection. Mol. Syst. Biol. 2, 0008 (2006). 2006.

57. Datsenko, K. A. \& Wanner, B. L. One-step inactivation of chromosomal genes in Escherichia coli K-12 using PCR products. Proc. Natl Acad. Sci. USA 97, 6640-6645 (2000)

58. Kobayashi, K. et al. Essential Bacillus subtilis genes. Proc. Natl Acad. Sci. USA 100, 4678-4683 (2003).

59. Sakaguchi, Y., Miyauchi, K., Kang, B. I. \& Suzuki, T. Nucleoside analysis by hydrophilic interaction liquid chromatography coupled with mass spectrometry. Methods Enzym. 560, 19-28 (2015).

60. Lin, $\mathrm{H}$. et al. CO2-sensitive tRNA modification associated with human mitochondrial disease. Nat. Commun. 9, 1875 (2018).

61. Markowitz, V. M. et al. IMG: the Integrated Microbial Genomes database and comparative analysis system. Nucleic Acids Res 40, D115-D122 (2012)

62. Kawabata, T. et al. GTOP: a database of protein structures predicted from genome sequences. Nucleic Acids Res 30, 294-298 (2002).

63. Finn, R. D. et al. InterPro in 2017-beyond protein family and domain annotations. Nucleic Acids Res 45, D190-D199 (2017)

\section{Acknowledgements}

We thank members of the Suzuki laboratory, especially Y. Sakaguchi and K. Miyauchi, for technical assistance and many helpful suggestions. This work was supported by the Grants-in-Aid for Scientific Research on Priority Areas from the Ministry of Education, 
Culture, Sports, Science, and Technology of Japan (26113003, 26220205, 18H05272 to T. S.), by a JSPS Fellowship for Japanese Junior Scientists (to Y. S. and S. K.).

\section{Author contributions}

Y.S. and S.K. performed a series of experiments. All authors discussed the results. Y.S and T.S. wrote this paper. Y.S., S.K., and T.S. designed the research structure. T.S. supervised all the work.

\section{Additional information}

Supplementary Information accompanies this paper at https://doi.org/10.1038/s41467019-10750-8.

Competing interests: The authors declare no competing interests.

Reprints and permission information is available online at http://npg.nature.com/ reprintsandpermissions/

Peer review information: Nature Communications thanks Lluis Ribas de Pouplana, and the other, anonymous, reviewer(s) for their contribution to the peer review of this work. Peer reviewer reports are available.
Publisher's note: Springer Nature remains neutral with regard to jurisdictional claims in published maps and institutional affiliations.

(c) (i) Open Access This article is licensed under a Creative Commons Attribution 4.0 International License, which permits use, sharing, adaptation, distribution and reproduction in any medium or format, as long as you give appropriate credit to the original author(s) and the source, provide a link to the Creative Commons license, and indicate if changes were made. The images or other third party material in this article are included in the article's Creative Commons license, unless indicated otherwise in a credit line to the material. If material is not included in the article's Creative Commons license and your intended use is not permitted by statutory regulation or exceeds the permitted use, you will need to obtain permission directly from the copyright holder. To view a copy of this license, visit http://creativecommons.org/ licenses/by/4.0/.

(C) The Author(s) 2019 